\title{
Information systems for collaborating versus transacting: Impact on manufacturing plant performance in the presence of demand volatility $^{\text {th }}$
}

\author{
Terence J.V. Saldanha ${ }^{\mathrm{a}, 1}$, Nigel P. Melville ${ }^{\mathrm{b}, *}$, Ronald Ramirez ${ }^{\mathrm{c}, 2}$, Vernon J. Richardson ${ }^{\mathrm{d}, 3}$ \\ a School of Business, Emporia State University, 1200 Commercial Street, Emporia, KS 66801, USA \\ b Stephen M. Ross School of Business, University of Michigan, 701 Tappan Street, Ann Arbor, MI 48109, USA \\ ${ }^{\text {c } B u s i n e s s ~ S c h o o l, ~ U n i v e r s i t y ~ o f ~ C o l o r a d o ~ D e n v e r, ~} 1250$ 14th St., Room 238, Denver, CO 80202, USA \\ d Sam Walton College of Business, University of Arkansas, 220N. McIlroy Ave., Fayetteville, AR 72701, USA
}

\section{A R T I C L E I N F O}

\section{Article history:}

Available online 27 July 2013

\section{Keywords:}

Demand volatility

E-collaboration

IT business value

Inventory performance

Labor productivity

Manufacturing performance

\begin{abstract}
A B S T R A C T
Research at the nexus of operations management and information systems suggests that manufacturing plants may benefit from the utilization of information systems for collaborating and transacting with suppliers and customers. The objective of this study is to examine the extent to which value generated by information systems for collaborating versus transacting is contingent upon demand volatility. We analyze a unique dataset assembled from non-public U.S. Census Bureau data of manufacturing plants. Our findings suggest that when faced with volatile demand, plants employing information systems for collaborating with suppliers and customers experience positive and significant benefits to performance, in terms of both labor productivity and inventory turnover. In contrast, results suggest that plants employing information systems for transacting in volatile environments do not experience such benefits. Further exploratory analysis suggests that in the context of demand volatility, these two distinct dimensions of IT-based integration have differing performance implications at different stages of the production process in terms of raw-materials inventory and finished-goods inventory, but not in terms of work-in-process inventory. Taken together, our study contributes to theoretical and managerial understanding of the contingent value of information systems in volatile demand conditions in the supply chain context.
\end{abstract}

(c) 2013 Elsevier B.V. All rights reserved.

\section{Introduction}

Increasing turbulence in the business environment has focused attention on organizational agility for business performance. In supply chains, such turbulence or environmental uncertainty characterized by demand volatility can introduce a range of problems including diminished service levels, reduced product revenues, increased stockouts, and lower profit margins (Kulp et al., 2004). Uncertainty can also result in a bullwhip effect as demand variability impacts are amplified in the form of higher inventory levels across the supply chain (Lee et al., 2004).

\footnotetext{
Disclaimer: Any opinions and conclusions expressed herein are those of the authors and do not necessarily represent the views of the U.S. Census Bureau. All results have been reviewed to ensure that no confidential information is disclosed.

* Corresponding author. Tel.: +1 734764 0199; fax: +1 7349368716.

E-mail addresses: tsaldanh@emporia.edu (T.J.V. Saldanha), npmelv@umich.edu (N.P. Melville),ronald.ramirez@ucdenver.edu (R. Ramirez), vrichardson@walton.uark.edu (V.J. Richardson).

1 Tel.: +1 620341 5693; fax: +1 6203416346 .

2 Tel.: +1 303315 8439; fax: +1 3033158084 .

3 Tel.: +1 479575 6803; fax: +1 4795754173 .
}

Information technology (IT) has emerged as a strategic resource for addressing the challenge of volatile demand conditions. In particular, IT provides capabilities for agility in volatile conditions by increasing visibility in the supply chain. For example, the IT system linking P\&G (Proctor and Gamble) to Wal-Mart's distribution centers automatically alerts $P \& G$ to pending stockouts, informing P\&G about when to make and ship products to Wal-Mart stores. Not only does this help P\&G reduce inventories, it also enables Wal-Mart's strategy of "low, everyday prices" (Wailgum, 2010). This example of IT-enabled interorganizational processes for supply chain collaboration illustrates the symbiotic nature of operations management $(\mathrm{OM})$ and information systems (IS) in practice.

Although such practical examples suggest a role of IT in the supply chain under volatile conditions, from a scholarly perspective, the lack of cross-fertilization between the OM and IS literatures (Venkatesh, 2010) has left open a gap in empirical evidence (Table 1). The contingent effect of uncertainty on the performance impact of various operations strategies has been studied by OM researchers (Table 1, Column A). A firm or plant perspective has been adopted in some studies (Anand and Ward, 2004; Inman et al., 2011), including analysis of how uncertainty moderates the association between decision integration (between manufacturing and 
Table 1

Prior research-moderating effect of environmental uncertainty.

\begin{tabular}{|c|c|c|}
\hline \multirow[t]{2}{*}{ Context } & \multicolumn{2}{|l|}{ Key independent variable } \\
\hline & Operations strategy (A) & Information technology (B) \\
\hline Firm/plant & $\begin{array}{l}\text { Moderating effect } \\
\text { - Manufacturing flexibility (Anand and Ward, 2004) } \\
\text { - Decision integration (O'Leary-Kelly and Flores) } \\
\text { No moderating effect } \\
\text { - Agile manufacturing (Inman et al., 2011) }\end{array}$ & $\begin{array}{l}\text { Moderating effect } \\
\text { - IT capability (Lu and Ramamurthy, 2004) } \\
\text { - IT leveraging competence (Pavlou and El Sawy, 2006) } \\
\text { - Strategic IT alignment (Tallon and Pinsonneault, 2011) } \\
\text { Mixed support for moderating effect } \\
\text { - IT investment (Li and Ye, 1999) } \\
\text { - Interorganizational systems (Sila, 2010) } \\
\text { No moderating effect } \\
\text { - IT capital (Melville et al., 2007) }\end{array}$ \\
\hline Supply chain & $\begin{array}{l}\text { Moderating effect } \\
\text { - Supply chain relationship quality (Fynes et al., 2004) } \\
\text { - Supply chain integration (Germain et al., 2008) } \\
\text { - Supply chain integration (Wong et al., 2011) } \\
\text { No moderating effect } \\
\text { - Integration (Koufteros et al., 2005) }\end{array}$ & $\begin{array}{l}\text { No moderating effect } \\
\text { • E-collaboration (Rosenzweig, 2009) }\end{array}$ \\
\hline
\end{tabular}

Note: Shaded cell indicates knowledge gap.

marketing) and perceived profitability (O'Leary-Kelly and Flores, 2002).

Other researchers have adopted a supply chain focus, some finding that the performance impacts of integration dimensions (e.g., supplier-customer relationships) are not moderated by environmental uncertainty (Koufteros et al., 2005). In contrast, a positive moderating effect of demand uncertainty was found for the link between supply chain relationship quality and performance (Fynes et al., 2004). Likewise, a positive moderating effect of environmental uncertainty was found for the association between customer integration and operational performance (Wong et al., 2011). Different drivers of process variability and financial performance were found to depend on demand predictability (Germain et al., 2008). Taken together, the literature presents mixed evidence of the moderating role of uncertainty on the performance impacts of operations strategies.

Regarding IT (Table 1, Column B), the moderating effect of uncertainty on the performance impact of IT has been studied by IS and OM researchers, with the firm or plant being the primary context. For example, there is evidence for a positive moderating effect of environmental volatility on the association between the strategic alignment of IT and firm performance (Tallon and Pinsonneault, 2011). Similarly, environmental dynamism was found to positively moderate the impact of IT investment on firm performance in terms of return on sales but not return on assets ( $\mathrm{Li}$ and Ye, 1999). Other studies found no support or unclear support for a moderating effect of environmental dynamism on performance (Melville et al., 2007; Sila, 2010).

One study using a supply-chain orientation analyzed the association between e-collaboration and performance, as well as the moderating effect of various contextual factors such as product complexity, environmental munificence, and market variability (Rosenzweig, 2009). The results indicated that market variability was not a significant moderator of the association between e-collaboration and operational performance. While the study yielded new insights about IT in supply chain contexts, many gaps remain regarding the moderating role of demand volatility on the IT-supply chain relationship and subsequent performance implications. First, we do not understand how value from different types of IT, such as IT for collaborating versus IT for transacting are moderated by demand volatility. This responds to frequently mentioned calls in prior research to disaggregate IT into more meaningful components (Aral and Weill, 2007; Bharadwaj et al., 1999; Devaraj and Kohli, 2003). Second, understanding is scant regarding moderating phenomena related to different demand patterns and uncertainties in the supply chain context (Rai et al., 2006), particularly with respect to two key performance metrics: inventory and productivity. Third, knowledge is limited regarding dynamic capabilities in the IT and supply chain context. Finally, to the best of our knowledge, no study has examined these phenomena using plant-level data with upstream and downstream perspectives, an approach that can provide new theoretical and practical insights. Indeed, as Yao and Zhu note (2012, p. 1053), “.. . although industry-level data analysis has been proved useful by prior studies, such aggregate data fall short of providing the granularity needed to investigate what exactly happens between firms in a supply chain".

Our objective in this study is to conduct interdisciplinary research that extends the OM and IS literatures by examining the relationships between IS for supply chain collaboration, demand volatility, and performance. To examine these relationships, we analyze a unique dataset that comprises a broad 21-industry sample of U.S. manufacturing plants, enabling us to address the following research question: What is the association between plant performance and IS used for transactions versus IS used for collaboration under varying conditions of demand volatility?

Building on the theory of dynamic capabilities (Teece et al., 1997), this paper extends OM and IS research by analyzing how the value of IT used for collaborating versus transacting in the supply chain context is differentially impacted by demand volatility. Specifically, what is new to the literature is (1) a conceptual pluralism that builds on theoretical knowledge from the OM and IS literatures to develop a research model; (2) a quantitative empirical analysis of new relationships focusing on how IT is used in supply chains using a unique and robust dataset; and (3) an evaluation of these new relationships across two dimensions of operational performance. Our paper is also beneficial to practitioners, helping managers to understand what types of IT applications in the supply chain can ameliorate problems arising from volatile demand conditions.

The remainder of the paper is organized as follows. In Section 2 we present theory and hypotheses. Section 3 describes the research design and methodology. In Section 4 we present our empirical results. Finally, in Section 5 we summarize our findings and contributions and describe limitations and future research directions.

\section{Theoretical development and hypotheses}

\subsection{Demand volatility and mitigation of negative impacts}

Demand volatility, defined as inconsistent, unstable, or highvariance demand for a company's goods and services, is a major contributor to overall environmental uncertainty and has 
been identified as an important factor influencing supply chains (Germain et al., 2008). Demand volatility can have many negative effects on firms, degrading customer service levels, reducing product revenues, and hampering overall operational and financial performance (Germain et al., 2008; Kulp et al., 2004). Many of these effects arise from distortion in production information as demand data is passed upward in the supply chain. Ultimately, volatility may engender a "bullwhip effect" as firms build safety stocks to buffer demand variations that occur due to economic shocks, promotions, and other factors (Lee et al., 2004).

A common mitigation mechanism of the negative impacts of demand volatility is enhanced information sharing. However, results from theoretical models of the value created through information sharing under varying demand conditions are mixed ( $\mathrm{Li}$ et al., 2005). For example, an upper bound may exist on the value of information sharing when demand is known, and speeding the physical flow of goods may be more valuable than enhancing information flow (Cachon and Fisher, 2000). Information sharing may also be of limited value when parameters of the demand process are known to both parties, because manufacturers can forecast demand without information from retailers (Raghunathan, 2001). Other theoretical models indicate that the value of information sharing can be higher when demand variance is higher (Lee et al., 2000). Taken together, these studies suggest that depending on the context, information sharing can be valuable in a volatile demand environment.

In contrast, there can be a reverse effect present in the IT value and demand volatility relationship (Li et al., 2005). The value of information sharing can be mitigated by demand variance (Chen, 1998), and can be higher when there is less variance in demand (Gavirneni et al., 1999; Schouten et al., 1994) or when demand is more correlated across time periods (Lee et al., 2000; Raghunathan, 2003). There are situations under changing demand conditions where sharing information is harmful to supply chain performance, and reducing lead times is more beneficial (Steckel et al., 2004; Treville et al., 2004). The breadth of information sharing between supply chain partners can also negatively affect supply chain flexibility (Gosain et al., 2005). In sum, there is broad agreement on potential underlying mechanisms and negative impacts of demand volatility on performance. However, there is not as much agreement regarding the role of information sharing in mitigating such negative impacts, exacerbated by the scarcity of quantitative empirical analyses to inform understanding.

\subsection{Information technology in the supply chain for transacting versus collaborating}

In the context of supply chains, the value of IT has been studied in terms of e-business transactions and their impact on sales and internal operations (Zhu and Kraemer, 2005). IT for transactions, including online selling and purchasing, is an enabler of performance. However, the mere use of technology is not a robust indicator of collaboration in the supply chain (Sabath and Fontanella, 2002). In contrast, IT for collaborating (sharing information related to design specifications, production schedules, etc.) represents a higher level of strategic partnership in the supply chain (Sabath and Fontanella, 2002). The role of information sharing in the supply chain is a topic of great managerial importance and has been a focus of research in the IS and OM literatures (e.g., Cachon and Fisher, 2000; Devaraj et al., 2007; Mukhopadhyay et al., 1995). Information is recognized as an important driver of supply chain performance by enabling firms to substitute information for inventory. The types of information shared typically include information related to inventory, sales, and production schedules (Lee and Whang, 2000). Analytical modeling has shown that such information sharing can reduce supply chain costs (Cachon and Fisher, 2000). Information exchange between Chrysler plants and their suppliers in the early 1990s was found to provide operational benefits to the plants, supporting the notion of benefits from sharing information in practice (Mukhopadhyay et al., 1995).

As the digital age progresses, the benefits of information sharing may increase. Recent research has shown that information exchange in partnerships can mediate the use of electronic business interchanges and enhance adaptability in the supply chain (Malhotra et al., 2007). Such IT-enabled supply chain integration can positively influence firm performance (Rai et al., 2006). In manufacturing and retail partnerships, the sharing of some types of information (e.g., store inventory) has been found to be relatively more beneficial than other types of information sharing (Kulp et al., 2004).

In this study, we combine the idea of examining the impact of demand volatility on the value of IS in the supply chain context with the idea that different underlying mechanisms may be at play across IT used for transacting versus IT used for collaborating (i.e., information sharing-based partnerships). Accordingly, we define two constructs that capture different applications (uses) of interorganizational IS. First, we define IT for transactions with suppliers and customers (ITT) as the use of IT for transactional purposes (e.g., online ordering). Second, we define IT for information partnering with suppliers and customers (ITIP) as the use of IT for various dimensions of collaboration through information sharing (e.g., information sharing of production schedules and design specifications). Thus, ITIP captures the use of IT at a more collaborative level than mere transactional use represented by ITT (Sabath and Fontanella, 2002).

\subsection{IT in the supply chain and plant performance}

Fig. 1 depicts our conceptual model. Our key theoretical argument is that while both types of IT use (ITT and ITIP)

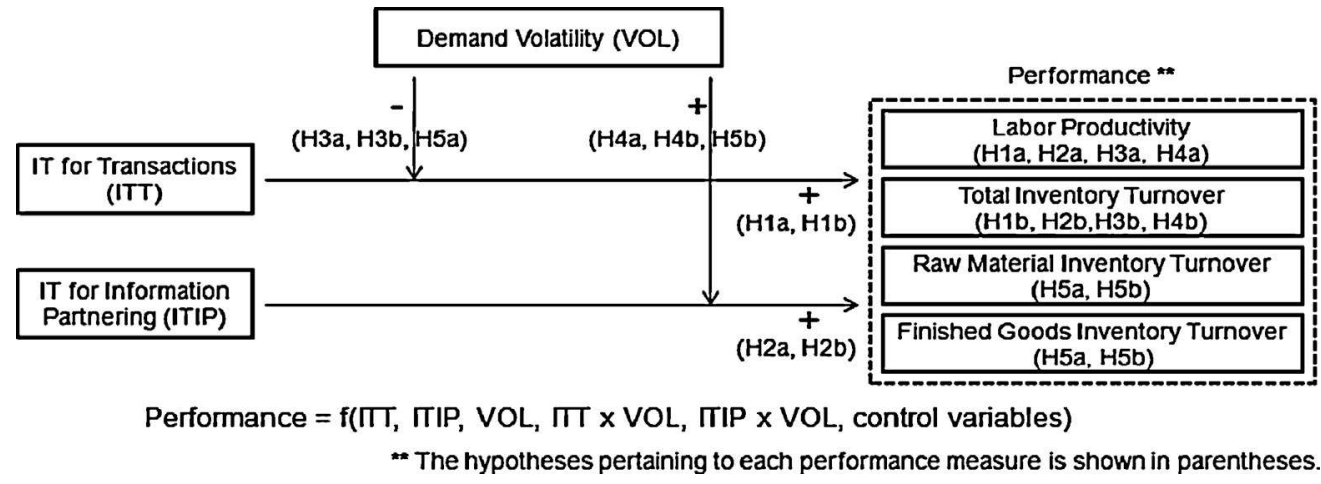

Fig. 1. Conceptual model. 
influence performance, the link between IT use and performance is differently moderated by demand volatility, based on whether IT is used for transactions (ITT) versus information partnering (ITIP). We now explicate our theoretical arguments underlying this conceptual model, and build our hypotheses.

\subsubsection{Value of IT for transacting (ITT)}

Information technology used for transactions (ITT) targets the automation of structured and routine processes. Such applications utilize IT as a substitute for repetitive human effort, improving the efficiency of transactions. In an inter-organizational setting, such use of IT helps reduce the costs of transactions between buyers and sellers, and operational costs within each organization (Srinivasan et al., 1994). The improvement in transaction timeliness and accuracy also enhances worker productivity. Workers become more productive through the reduction in idle time due to fewer raw material stockouts and the availability of the right parts. Workers produce higher quality output and perform less rework due to accurate communication of partner needs, thus improving the efficiency of manufacturing work. In short, through the automation of inter-organizational transactions and replacement of manual tasks with electronic communication, the use of ITT can improve labor productivity.

The use of ITT can also contribute to inventory performance. IT for transactions enables electronic tracking and regulating the flow of materials in relation to requirements and the purchasing of maintenance, repair, and operations (MRO) and raw product parts (Mukhopadhyay et al., 1995). Electronic ordering and procurement can help direct suppliers to deliver materials at the appointed time resulting in improved inventory turnover (Dehning et al., 2007). Web-based procurement can go even further in performance improvement by helping to reduce search-related costs in purchasing activities as well as to improve sales and internal operational efficiencies (Zhu and Kraemer, 2005). Hence:

H1a. The use of IT for transactions with suppliers and customers (ITT) is positively associated with performance as measured by labor productivity.

H1b. The use of IT for transactions with suppliers and customers (ITT) is positively associated with performance as measured by inventory turnover.

\subsubsection{Value of IT for information partnering (ITIP)}

As discussed earlier, information partnering through information sharing can benefit supply chain members and forms the core foundation of supply chain collaboration (Lee and Whang, 2000). Information-based partnerships enable supply chain members to informate and transform key business processes (Zuboff, 1985) and can thus improve the planning of operational tasks and improve coordination. The more collaborative use of IT can result in a better strategic and functional fit of internal production processes and external inter-organizational processes, resulting in positive performance impacts that include operating flexibility, production throughput, and labor productivity (Henderson and Venkatraman, 1993; Tallon, 2007).

Information partnering also provides the ability to improve forecasts and coordinate inventory and production decisions through a shared understanding of performance issues (Rai et al., 2006). ITIP improves supply chain visibility and can help managers optimize the flow of materials and employ inventory management techniques that might otherwise be difficult. Through enhanced supply-chain visibility, ITIP can also facilitate the synchronization of activities of the supply chain partners (Bharadwaj et al., 2013). For example, ITIP can facilitate postponement (producing closer in time to demand) helping to keep inventory costs low. We thus hypothesize:
H2a. The use of IT for information partnering with suppliers and customers (ITIP) is positively associated with performance as measured by labor productivity.

H2b. The use of IT for information partnering with suppliers and customers (ITIP) is positively associated with performance as measured by inventory turnover.

\subsection{Contingent value of IT in the supply chain}

The value of IT resources must be viewed in conjunction with the firm's competitive environment (Melville et al., 2004). As such, we draw upon the theoretical framework of Weill (1992) to explicate how value created from the use of non-homogenous IT components with supply chain partners (ITT and ITIP) is different under different conditions of demand volatility.

The theory of dynamic capabilities posits that capabilities that facilitate re-alignment of resources enable firms to adapt in volatile conditions (Teece et al., 1997). As discussed later in more detail, we posit that ITIP, by improving supply chain visibility and facilitating collaboration through closer relationships with customers and suppliers, provides dynamic capabilities that can help firms adapt in volatile demand conditions and achieve better performance. In contrast, we argue that ITT is unlikely to be a source of dynamic capabilities, but is rather a commodity-like resource and may be more beneficial in stable environments. Thus, as research suggests, turbulent environments, as opposed to stable environments, require different IT capabilities for superior performance (Wade and Hulland, 2004).

\subsubsection{Contingent value of IT for transactions (ITT)}

The focus of ITT is on the automation of transaction processes and the improvement of efficiency. Transactional IT relationships typically do not involve levels of trust, commitment, or planning found in collaborative IT relationships. For instance, firms can use IT for electronic data interchange (EDI) and JIT (just-in-time) without achieving a level of integration where design and long-term strategic data are shared (Spekman et al., 1998). In a supply chain context Dong et al. (2009, p. 23) suggest that the value of "commoditylike" IT resources that do not "meet the RBV (resource-based view) criteria" diminishes under competition.

ITT is an example of a commodity-like resource that may be less valuable in volatile conditions. ITT can facilitate integration of transactions but not other elements required to manage volatile conditions (e.g., strategic planning). ITT can improve performance in standard, repetitive processes (Aral and Weill, 2007), but ITT lacks the ability to adapt and restructure with volatile demand conditions. Prior research suggests that IT based on efficiency can be a "disabler of flexibility" and hinder agility (Knoll and Jarvenpaa, 1994, p.3; Overby et al., 2006) because such use of IT can "automate the status quo, freezing the organization into patterns of behavior and operations that resolutely resist change" (Allen and Boynton, 1991, p. 435). Efficiency-based IT such as ITT can often result in operational practices designed to routinize change, which, in dynamically changing environments are less beneficial (Kwon and Watts, 2006). ITT is thus "inside-out" in nature and its value is likely to be stronger in stable rather than in turbulent environments (Wade and Hulland, 2004, p. 126). Because ITT typically does not involve cross-organizational long-term planning (Spekman et al. 1998), volatile demand can have detrimental effects on the value of ITT. As a result, in volatile demand conditions, the role of ITT in improving operational performance may be diminished.

We have argued in rather general terms for the negative moderating role of volatility on the association between ITT and performance. Although there may be nuances between the moderating role of volatility on the two performance measures examined 
in this study (labor productivity and inventory turnover), we posit that the moderating role of volatility will be observed for both performance measures. For example, with regard to labor productivity, although ITT improves productivity by improving accuracy and eliminating paperwork, it is less likely to help build agile partnerships with trading partners, has negligible impact on planning, and does little to reduce uncertainty faced by trading partners in determining future demand. This is consistent with dynamic capabilities theory, as IT for transacting does little to enhance learning, reconfiguration, and transformation (Teece et al., 1997). With regard to inventory turnover, prior research suggests that orders are a result of "conjectures by the buyer" and can "distort the true dynamics of the marketplace," exacerbating the bullwhip effect (Lee and Whang, 2000, p. 4). Hence, ITT may set forth chain reactions of ordering for the firm and to the extent that it automatically does so, ITT may negatively impact inventory performance in volatile demand conditions. In sum, based on theoretical arguments derived from the literature and the lack of ITT's ability to confer dynamic capabilities, we argue that the ability of ITT to improve performance (productivity and inventory turnover) is mitigated by demand volatility. Hence:

H3a. Demand volatility negatively moderates the association between IT for transactions (ITT) and performance as measured by labor productivity.

H3b. Demand volatility negatively moderates the association between IT for transactions (ITT) and performance as measured by inventory turnover.

\subsubsection{Contingent value of IT for information partnering (ITIP)}

As our literature review suggests, the value created via information partnering in the presence of turbulent demand conditions has yet to be analyzed empirically. Some analytic modeling research suggests that information sharing across the supply chain is more valuable when parameters of the demand process are unknown (Raghunathan, 2001) or demand variability is high (Bourland et al., 1996; Lee et al., 2000). In contrast, it is possible that in changing, volatile environments, information shared may be less valuable as it can be inaccurate, unavailable, or obsolete (Bourgeois and Eisenhardt, 1988). As discussed earlier, some analytic modeling research also suggests that under high demand variance, the value of information sharing may be limited (Chen, 1998).

We argue that ITIP can be a source of dynamic capabilities (Teece et al., 1997). ITIP can improve supply chain visibility, helping the firm to reconfigure its resources in the face of dynamic, changing business environments (Gosain et al., 2005). In turbulent environments, ITIP can help firms to develop dynamic capabilities to enhance alertness, better predict the future, and increase competitiveness (Granados and Gupta, 2013). In volatile conditions, ITIP can provide new information to managers and enhance co-ordination, integration, learning, reconfiguration, and transformation (Teece et al., 1997). In turn, the ability of the firm to respond to volatile demand conditions is likely to be enhanced. For example, electronic sharing of information with its component suppliers improved Cisco's agility to cope with changing demand (Dong et al., 2009). These information-based partnerships improved Cisco's ability to rapidly respond to demand changes. Increased visibility in the supply chain facilitated by ITIP helps firms respond to demand changes and can facilitate more efficient allocation of resources. Thus, in volatile conditions, ITIP is likely to help decision makers explore alternative courses of action and boost productivity by reducing waste and creating new options.

ITIP can also help firms better manage inventory in volatile conditions. First, inventory is often held to manage uncertainty (Anand and Ward, 2004). ITIP can provide accurate and timely exchange of information that mitigates uncertainty in decision-making and can help supply chain managers co-ordinate material movements between trading partners and reduce inventory costs (Strader et al., 1999). Second, through IT-based sharing of information with suppliers and customers, firms can better match supply with customer demand and anticipate changes in the marketplace (Li et al., 2006). Third, ITIP can help supply chain participants adapt to changes in demand through improved scheduling and inventory management techniques (Kulp et al., 2004). Finally, ITIP can help re-align production schedules with more flexibility in manufacturing changeovers so as to adjust to changes in customer demand and better manage inventory.

In sum, in volatile conditions, the benefits of ITIP can be reinforced through improved decision-making, better matching of supply to customer demand, improved scheduling and inventory management techniques, and greater flexibility. Thus ITIP is a distinctive source of dynamic capabilities in the supply chain context that can play an important role in supporting flexibility, reducing information asymmetry, and improving operational performance in volatile conditions. Conversely, in stable environments, ITIP may not provide new information and may be of less incremental value (Lee et al., 2000; Melville et al., 2007). Hence, based on the ability of ITIP to confer dynamic capabilities in volatile demand conditions and potentially ameliorate the negative effects of volatility, we hypothesize:

H4a. Demand volatility positively moderates the association between IT for information partnering (ITIP) and performance as measured by labor productivity.

H4b. Demand volatility positively moderates the association between IT for information partnering (ITIP) and performance as measured by inventory turnover.

\subsection{Exploratory analysis: Disaggregation of inventory}

It is possible that the moderating role of volatility may be different based on where in the value chain inventory is measured. As Rajagopalan and Malhotra (2001, p. 18) note, "the nature of various stages of inventory is such that the rate of improvement may differ across stages". We explore whether the moderating role of demand volatility is seen at the backend, front end, or in-production stage of manufacturing. Such an analysis can provide indications of where investment in IS may be more applicable during situations of volatile demand.

Prior research also motivates us to consider the moderating role of demand volatility on IT value across disaggregated measures of inventory. For example, Capkun et al. (2009) find that improvement to inventory in the backend (raw material inventory) is the most important driver of firm performance as measured by earnings and gross profit. Research has also considered how adoption of supply chain management systems differently affects raw materials inventory (RMI), work-in-process inventory (WIPI), and finished goods inventory (FGI) (Dehning et al., 2007).

We posit that the value generated by ITT and ITIP at the outward (front-end and back-end) interfaces with supply chain partners (RMI and FGI) would be dramatically affected by volatile demand conditions. Two primary reasons underlie this proposition. First, ITT and ITIP represent interorganizational use of IT. Hence, the moderating role of volatility on value from ITT and ITIP is more likely to be seen at the front end and backend stage of manufacturing, consistent with the argument that IT value is best manifested at the business process activity nearest the point of application of IT (Tallon et al., 2000). Second, the management of RMI and FGI requires greater coordination with suppliers and customers than the management of WIPI (Callen et al., 2000). In contrast, WIPI is more likely affected by internal process improvements and production systems, rather than by interorganizational IT use with 
customers and suppliers (Rajagopalan and Malhotra, 2001). Hence, in volatile demand conditions, collaborating with customers and suppliers through IT is more likely to provide firms with improved capabilities in managing customer orders and purchasing, and optimizing finished goods and raw material stock as well as backlog. In line with these arguments and given the lack of prior research, we posit two exploratory hypotheses:

H5a ((exploratory)). Demand volatility negatively moderates the association between IT for transactions (ITT) and performance as measured by RMI turnover and FGI turnover.

H5b ((exploratory)). Demand volatility positively moderates the association between IT for information partnering (ITIP) and performance as measured by RMI turnover and FGI turnover.

\section{Research design and methodology}

Our empirical setting comprises manufacturing plants in the U.S. We utilize micro-data from four U.S. Census Bureau (USCB) plantlevel datasets, which have been used in prior research (Atrostic and Nguyen, 2005; Black and Lynch, 2001): the Census of Manufactures (CM), Annual Survey of Manufactures (ASM), the Computer Network Use Supplement (CNUS) conducted in 1999, and the Annual Survey of Plant Capacity Utilization (SPCU). These data sources provide fine-grained data on IT use and plant performance appropriate for our analysis (Appendix A).

\subsection{Variables}

\subsubsection{Dependent variables}

We use performance measures used in prior research (Table 2). First, labor productivity (LP) is an important measure of process efficiency and is a widely used metric of manufacturing operational performance in the OM and IS literatures (e.g., Banker et al., 2006; Heim and Peng, 2010; MacDuffie et al., 1996; Melville et al., 2007; Shah and Ward, 2003). We use total value of shipments as a measure of gross output, and total number of employees in the plant as our measure of labor (Atrostic and Nguyen, 2005; McGuckin and Nguyen, 1995). Second, Total inventory (TI), defined as the logged ratio of the sum of raw-materials, work-in-process, and finishedgoods inventory to total value of shipments (Lieberman et al., 1999), is a frequently used performance measure to assess the effectiveness of lean production practices (Levy, 1997) and supply chains (Gunasekaran et al., 2001). Finally, Raw-materials inventory (RMI), Work-in-process inventory (WIPI), and Finished-goods inventory (FGI) are defined as the log of the ratio of the respective inventory component to the total value of shipments (Lieberman et al., 1999).

\subsubsection{Independent variables}

ITT and ITIP are count-based composite measures (Table 2). ITT consists of the use of IT by the plant for transactional purposes with suppliers and customers, while ITIP consists of various dimensions of information sharing by the plant with suppliers and customers. Consistent with prior OM and IS research (e.g., Banker et al., 2006; Heim and Peng, 2010; Kulp et al., 2004), we count (sum) the number of IT for transaction measures (ITT) and IT for information sharing measures (ITIP) used by the plant as reported in the CNUS. The ITT measures are transactional in nature, while the ITIP measures are collaborative in nature and are suggestive of a more tightly coupled IT-enabled integration between the focal plant and its customers and suppliers than mere transactional IT use (Sabath and Fontanella, 2002). Since ITT and ITIP capture how IT is used, our findings are largely generalizable across eras and are not bound to specific technologies used in a particular era. Our approach is also consistent with research that recommends examination of performance implications of IT employing nuanced measures of how IT is used, rather than deployment of specific technologies (Devaraj and Kohli, 2003).

Volatility in demand (VOL) for a plant in a given year is measured as the coefficient of variation of (the log of) plant output (total value of shipments) over the five years prior to the year of interest. This measure is consistent with previous IT-based research involving volatility (Dewan et al., 2007; Kobelsky et al., 2008). ${ }^{4}$

\subsubsection{Control variables}

Capital and materials control for investments in plant, equipment, and materials that may affect productivity via substitution for labor (MacDuffie et al., 1996) and affect inventory levels (Kolias et al., 2011). ${ }^{5}$ Plant size accounts for scale effects on productivity (Banker et al., 2006) and inventory (Shah and Ward, 2003). Plant capacity utilization (PCU) may impact productivity for technical reasons (Brush and Karnani, 1996), and inventory through its impact on operations planning (Gunasekaran et al., 2001). AGE accounts for potential learning curve influences (Shah and Ward, 2003). Industry concentration (CONC) controls for influences of competition on productivity (Bharadwaj et al., 1999) and inventory (Cachon and Olivares, 2010). ${ }^{6}$ Output growth controls for influence of change in plant output on inventory levels (Rajagopalan and Malhotra, 2001). PROD helps account for influence of product variety on inventory (Mukhopadhyay et al., 1995). The multiunit indicator accounts for the potential influence of the number of plant locations (Rajagopalan and Malhotra, 2001). Other controls for productivity are energy (Atrostic and Nguyen, 2005), share of exports (Wagner, 2002), and worker skill mix (Berman et al., 1994). Lastly, industry dummies and location dummies control for industry and regional idiosyncrasies.

\subsection{Empirical models}

To test the productivity hypotheses (H1a-H4a), we estimate: $\mathrm{LP}=\beta_{10}+\beta_{11} \mathrm{ITT}+\beta_{12} \mathrm{ITIP}+\beta_{13} \mathrm{VOL}+\beta_{14} \quad(\mathrm{ITT} \times \mathrm{VOL})+\beta_{15}$ $($ ITIP $\times$ VOL $)+\beta_{1 \mathrm{c}} \mathbf{X}_{\mathbf{p}}+\varepsilon_{1}$, where $\mathbf{X}_{\mathbf{p}}$ is the vector of control variables. To test $\mathrm{H} 1 \mathrm{~b}-\mathrm{H} 4 \mathrm{~b}$, we estimate: $\mathrm{TI}=\beta_{20}+\beta_{21} \mathrm{ITT}+\beta_{22} \mathrm{ITIP}+\beta_{23} \mathrm{VOL}+\beta_{24} \quad(\mathrm{ITT} \times \mathrm{VOL})+\beta_{25}$ $($ ITIP $\times$ VOL $)+\beta_{2 c} \mathbf{X}_{\mathbf{i}}+\varepsilon_{2}$, where $\mathbf{X}_{\mathbf{i}}$ is the vector of control variables. Since the dependent variable is the $(\log )$ ratio of inventory to sales, $\mathrm{H} 3 \mathrm{~b}$ posits a positive sign on $\beta_{24}$, and $\mathrm{H} 4 \mathrm{~b}$ posits a negative sign on $\beta_{25}$. To test $\mathrm{H} 5$, we estimate: $\quad \mathrm{INV}=\beta_{0}+\beta_{1} \mathrm{ITT}+\beta_{2} \mathrm{ITIP}+\beta_{3} \mathrm{VOL}+\beta_{4} \quad(\mathrm{ITT} \times \mathrm{VOL})+\beta_{5}$ $($ ITIP $\times$ VOL $)+\beta_{\mathrm{c}} \mathbf{X}_{\mathbf{i}}+\varepsilon$; INV is alternatively RMI, WIPI, and FGI.

\subsection{Estimation approach}

Since our dependent variables are continuous, we use the (crosssectional) ordinary least squares (OLS) approach to estimate our models for the year 1999. While the benefits of cross-sectional estimation are well known, panel estimation models account for potential unobserved heterogeneity across individual units (Greene, 2003). Moreover, with cross-sectional estimation, the observed relationships are representative of the population at a single point in time, and do not account for temporal aspects. In

\footnotetext{
${ }^{4}$ We thank an anonymous reviewer for insights related to the measurement of demand volatility.

5 We follow prior studies (e.g., Atrostic and Nguyen, 2005) and use book values of capital as a proxy for capital. We use the standard perpetual inventory management method (Black and Lynch, 2001) to compute capital if unavailable.

${ }^{6}$ CONC is analogous to four-firm concentration ratio (Bharadwaj et al., 1999). Though CONC does not capture concentration ratio precisely, there is likely high correlation between our measure and the actual, because the ASM is weighted toward large plants, is well representative of industries, and accounts for roughly $98 \%$ of the value of shipments in the entire manufacturing sector (U.S. Census Bureau, 2001).
} 
Table 2

Variables.

\begin{tabular}{|c|c|c|}
\hline Variable & Name & Description \\
\hline Labor productivity & LP & Log(total value of shipments/number of employees) \\
\hline Total inventory & TI & $\log$ (value of total inventory/total value of shipments) \\
\hline Raw materials inventory & RMI & Log(value of raw materials inventory/total value of shipments) \\
\hline Work-in-process inventory & WIPI & Log(value of work-in-process inventory/total value of shipments) \\
\hline Finished-goods inventory & FGI & Log(value of finished-goods inventory/total value of shipments) \\
\hline IT for transactions & ITT & $\begin{array}{l}\text { Count of the following nine binary transactional IT measures. Use of computer networked business processes for: ( } 1 \text { ) } \\
\text { ordering from vendors; ( } 2 \text { ) payment to vendors; ( } 3 \text { ) access to vendors' products or catalogs; ( } 4 \text { ) online bidding; } 5 \text { ) } \\
\text { using electronic marketplaces; ( } 6 \text { ) access by customers to your products or catalogs; ( } 7 \text { ) ordering by customers; ( } 8 \text { ) } \\
\text { payment by customers; ( } 9 \text { ) customer support }\end{array}$ \\
\hline IT for information partnering & ITIP & $\begin{array}{l}\text { Count of the following twelve binary information sharing measures. Online information sharing for: (1) design } \\
\text { specifications with external customers; (2) design specifications with external suppliers; ( } 3 \text { ) demand projections with } \\
\text { external customers; (4) demand projections with external suppliers; (5) inventory data with external customers; }(6) \\
\text { inventory data with external suppliers; ( } 7 \text { ) production schedules with external customers; (8) production schedules } \\
\text { with external suppliers; (9) logistics or transportation with external customers; (10) logistics or transportation with } \\
\text { external suppliers; (11) product descriptions or catalog with external customers; (12) product descriptions or catalog } \\
\text { with external suppliers }\end{array}$ \\
\hline Volatility & VOL & Coefficient of variation of log (total value of shipments) of the plant over the five years prior to the year of interest \\
\hline
\end{tabular}

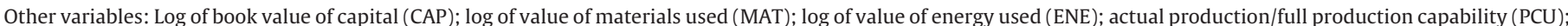

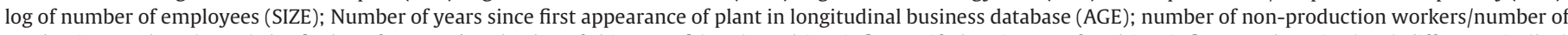

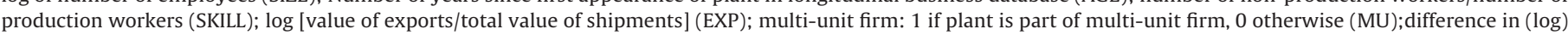

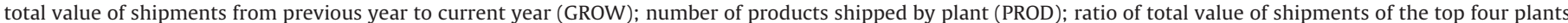

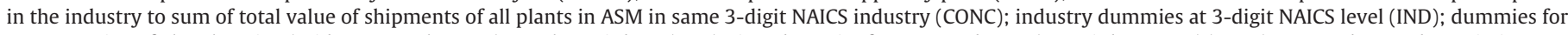

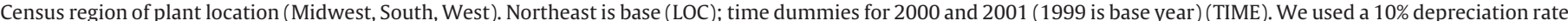

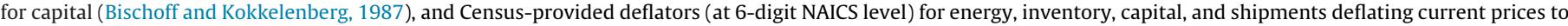
1997 prices.

longitudinal analyses, it is possible to capture changes occurring within plants across time and to make inferences that are not as sensitive to between-plant variation (Greene, 2003). Hence, to add robustness to our cross-sectional estimations, we extend our analysis and estimate panel regressions. ${ }^{7}$

Our rich dataset allows us to estimate panel models. With the exception of the IT variables, ${ }^{8}$ all the variables are available for multiple years from 1999 to 2001. Consistent with prior research in economics and IS (Black and Lynch, 2001; Bresnahan et al., 2002; Brynjolfsson et al., 2002; Joshi et al., 2010; Ramirez et al., 2010), we extend the CNUS data by assuming that plant IT usage reported in the 1999 CNUS is the same in 2000 and 2001. By doing so, we are able to construct a longitudinal dataset, consistent with recommendations in prior IS literature (Banker et al., 2006; Devaraj and Kohli, 2003; Melville et al., 2004; Srinivasan et al., 1994). This data extension method is reasonable for several reasons that we summarize here and detail in Appendix C: (1) e-business systems and their deployments are important IT investments that require considerable time for planning and implementation; (2) use of multiple items suggests that it is very unlikely that over the relative short span of extension $(2000,2001)$, a plant's use of IT would change significantly; (3) no significant quality change in e-business technology took place during 1999-2001; and (4) system factors such as those that we consider here have been shown to evolve simultaneously over time (e.g., Brynjolfsson and Hitt, 2003).

Our panel estimations, detailed in Appendix D, employ fixedeffects (FE) models which account for plant-level heterogeneity (Greene, 2003). To estimate the coefficients of (time-invariant) ITT and ITIP, we use Hausman-Taylor (HT) models (Hausman and Taylor, 1981).

In sum, our approach consists of estimating OLS, FE, and HT models. The panel models (FE and HT) serve to add robustness to our cross-sectional estimations. For each model, we first report the

\footnotetext{
7 We thank an anonymous reviewer for insights related to the use of crosssectional versus panel estimation.

8 The ASM and SPCU data were collected annually in years 1999-2001; the CNUS IT data were collected in 1999 (Appendix A).
}

model without interaction terms and then the model with interaction terms.

\section{Results}

Table 3 shows the descriptive statistics and correlations for the productivity model. ${ }^{9}$ We note that volatility is negatively correlated with labor productivity and positively correlated with inventory (Appendix B), similar to prior research (Anand and Ward, 2004; Anderson et al., 2000).

\subsection{Value of ITT and ITIP under volatile demand conditions}

Table 4 shows cross-sectional and panel results for the productivity models. The coefficients of ITT and ITIP are statistically non-significant (column 1), providing no support for H1a and H2a. ${ }^{10}$ In contrast, consistent with $\mathrm{H} 3 \mathrm{a}$, we find that the interaction of ITT and VOL is negative and statistically significant $\left(\beta_{14}=-1.046\right.$, $p<0.05) .{ }^{11}$ Conversely, the interaction of ITIP and VOL is positive and statistically significant, supporting $\mathrm{H} 4 \mathrm{a}\left(\beta_{15}=0.628, p<0.05\right)$. An $F$-test of joint significance of the interaction terms is rejected $(p<0.01)$, suggesting rejection of the null that the interaction terms are jointly zero. In line with prior research (Anderson et al., 2000), VOL has a negative and significant coefficient. ${ }^{12}$ The results are similar in cross-sectional and panel models.

Estimation results for the total inventory model (Table 5 ) show that the coefficients of ITT and ITIP are non-significant $(p>0.10)$;

\footnotetext{
${ }^{9}$ Statistics for the Inventory models (Appendix B) are similar. The samples are fairly well representative of the population in 3-digit NAICS manufacturing industries. The industry-wise sample distributions of plants are available from the authors on request.

10 Examining the marginal effects using estimations from the full model in column 2 also provides no support for $\mathrm{H} 1 \mathrm{a}$ and $\mathrm{H} 2 \mathrm{a}$.

11 Though we interpret the cross-sectional model estimates, the hypotheses results are qualitatively similar in the panel models.

12 Other control variables are also, in general, in expected directions. For example, Capital and Materials have positive coefficients. The negative sign of Size is expected since, like prior research (Atrostic and Nguyen, 2005), we have Labor in the denominator of the dependent variable. The net coefficient of (log) Labor is $(1-0.699)=0.301$.
} 
Table 3

Summary statistics and correlations for productivity model.

\begin{tabular}{|c|c|c|c|c|c|c|c|c|c|c|c|c|c|c|c|c|}
\hline & & Mean & SD & 1 & 2 & 3 & 4 & 5 & 6 & 7 & 8 & 9 & 10 & 11 & 12 & 13 \\
\hline 1 & LP & 5.58 & 0.77 & 1 & & & & & & & & & & & & \\
\hline 2 & ITT & 2.63 & 2.08 & 0.001 & 1 & & & & & & & & & & & \\
\hline 3 & ITIP & 2.20 & 2.42 & -0.01 & $0.46^{*}$ & 1 & & & & & & & & & & \\
\hline 4 & Volatility & 0.03 & 0.01 & $-0.12^{*}$ & -0.01 & -0.03 & 1 & & & & & & & & & \\
\hline 5 & Capital & 10.36 & 1.38 & $0.35^{*}$ & $0.15^{*}$ & $0.09 *$ & $-0.09 *$ & 1 & & & & & & & & \\
\hline 6 & Materials & 10.62 & 1.39 & $0.59^{*}$ & $0.13^{*}$ & $0.09^{*}$ & $-0.18^{*}$ & $0.74^{*}$ & 1 & & & & & & & \\
\hline 7 & Energy & 6.76 & 1.33 & $0.33^{*}$ & $0.08^{*}$ & 0.02 & $-0.16^{*}$ & $0.83^{*}$ & $0.69^{*}$ & 1 & & & & & & \\
\hline 8 & PCU & 0.68 & 0.21 & $0.18^{*}$ & $-0.07^{*}$ & $-0.09^{*}$ & $-0.20^{*}$ & $0.17^{*}$ & $0.21^{*}$ & $0.24^{*}$ & 1 & & & & & \\
\hline 9 & Size & 5.92 & 0.98 & -0.03 & 0.19* & 0.19* & $-0.17^{*}$ & $0.72^{*}$ & $0.68^{*}$ & $0.63^{*}$ & $0.13^{*}$ & 1 & & & & \\
\hline 10 & Multiunit & 0.95 & 0.23 & $0.13^{*}$ & 0.02 & 0.01 & $-0.04^{*}$ & $0.23^{*}$ & $0.20^{*}$ & $0.22 *$ & $0.04^{*}$ & $0.16^{*}$ & 1 & & & \\
\hline 11 & Plant age & 24.23 & 6.07 & -0.01 & $0.05^{*}$ & $0.07^{*}$ & $-0.06^{*}$ & $0.14^{*}$ & $0.07^{*}$ & $0.14^{*}$ & -0.01 & $0.12^{*}$ & $0.07^{*}$ & 1 & & \\
\hline 12 & Share of exports & -2.79 & 1.71 & $-0.1^{*}$ & $0.06^{*}$ & $0.08^{*}$ & $0.04^{*}$ & $0.04^{*}$ & $-0.04^{*}$ & -0.02 & $-0.1^{*}$ & $0.04^{*}$ & -0.00 & $-0.04 *$ & 1 & \\
\hline 13 & Skill ratio & -1.43 & 0.68 & 0.01 & 0.03 & $0.04 *$ & $0.11^{*}$ & $-0.09 *$ & $-0.12^{*}$ & $-0.2^{*}$ & $-0.2^{*}$ & $-0.1^{*}$ & -0.02 & 0.01 & $0.24^{*}$ & 1 \\
\hline 14 & Concentration & 0.06 & 0.05 & $0.14^{*}$ & $0.06^{*}$ & $0.04^{*}$ & $0.06^{*}$ & $0.13^{*}$ & $0.15^{*}$ & $0.04^{*}$ & -0.03 & $0.12^{*}$ & $0.05^{*}$ & -0.02 & $0.06^{*}$ & $0.11^{*}$ \\
\hline
\end{tabular}

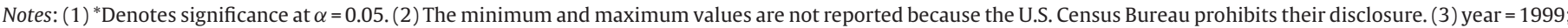
$n=3032$.

thus $\mathrm{H} 1 \mathrm{~b}$ and $\mathrm{H} 2 \mathrm{~b}$ are not supported. However, consistent with $\mathrm{H} 3 \mathrm{~b}$, the interaction of ITT and VOL is positive and statistically significant $\left(\beta_{24}=1.642, p<0.05\right)$. Also, the interaction of ITIP and VOL is negative and statistically significant $\left(\beta_{25}=-1.488, p<0.01\right)$, supporting H4b. Again, an $F$-test of joint significance of the interaction terms is rejected $(p<0.01)$, suggesting rejection of the null that the interaction terms are jointly zero. Finally, VOL has a positive and statistically significant coefficient, in line with the argument that plants facing high volatility in demand tend to have higher inventory to buffer against the effects of volatility (Anand and Ward, 2004). Results are similar in cross-sectional and panel models.

Taken together, we find strong support for $\mathrm{H} 3$ and $\mathrm{H} 4$, whereas $\mathrm{H} 1$ and $\mathrm{H} 2$ are not supported. Per our estimates, in high-volatile demand conditions, a plant high on ITIP experiences, on average, a reduction of approximately 0.2 in TI, i.e., a reduction in the total inventory to sales ratio of $1 / \exp (0.2)$ or approximately $18 \%$ compared to a plant low on ITIP. Similar interpretation of the productivity estimation suggests that plants high in ITIP enjoy, on average, a $9.5 \%$ increase in productivity in high volatile demand conditions. This suggests that the moderating role of volatility is also economically significant. Similar interpretations of the ITT interaction terms show that VOL negatively moderates the ITTperformance relationship.

\subsection{Exploratory analysis results: Disaggregation of inventory}

Table 6 shows results for our exploratory analysis. The interaction of ITT and VOL is positive and statistically significant for $\operatorname{RMI}\left(\beta_{4}=1.42, p<0.05\right)$ and FGI $\left(\beta_{4}=4.38, p<0.05\right)$, while it is nonsignificant for WIPI $(p>0.10)$. Similarly, the interaction of ITIP and VOL is negative and statistically significant for RMI $\left(\beta_{5}=-1.58\right.$, $p<0.05)$ and FGI $\left(\beta_{5}=-4.39, p<0.01\right)$, while it is non-significant for WIPI $(p>0.10)$. An $F$-test of joint significance of the interaction terms rejects the null in the RMI model $(p<0.05)$ and the FGI model $(p<0.01)$, but does not reject the null in the WIPI model $(p>0.10)$. Taken together, these results support H5a and H5b, in line with our theory that the moderating effect will be observed at the plant's outer interfaces (RM and FG) rather than at WIP. Notably, in crosssectional estimations, the ITT coefficient is negative and significant for RMI $\left(\beta_{1}=-0.03, p<0.05\right)$ and FGI $\left(\beta_{1}=-0.05, p<0.10\right)$, but not significant for WIPI $(p>0.10)$.

\subsection{Robustness checks}

First, we conduct several sensitivity analyses on the independent and dependent variables. To assess the sensitivity of ITT and ITIP to the inclusion of particular measures, we experiment by dropping some measures and re-analyzing. The results remain unchanged suggesting that a small number of measures are not driving the results. Also, although we treat ITT and ITIP as formative (use of any measure does not imply use of others) and hence not subject to tests of internal consistency (Diamantopoulos and Winklhofer, 2001), the Cronbach alpha reliability coefficients are above the threshold of 0.7 (Nunnally, 1967). The findings are unchanged when we separately standardized and de-meaned the measures comprising ITT and ITIP. We also obtain similar results when we calculated VOL over the previous three (rather than five) years. We believe, however, that a five-year period better captures variability in demand. Another concern is that IT may only be accessed by a part of the workforce. In the absence of a direct count of workers with access to ITT and ITIP, we re-estimate the productivity models separately using two proxies: Percent of plant employees with access to any kind of internet; and the number of non-production workers. Both yield the same inferential result patterns.

Second, given the unbalanced panel and the use of FE models, sample bias is a potential concern. To address this, we follow Wooldridge's (2002) method, which suggests that sample bias is not problematic if the selection is uncorrelated with the idiosyncratic error. We re-estimate the FE models by adding a selection indicator with a one-period lag (Wooldridge, 2002). This variable models the presence of plants by indicating which years are missing for each plant. ${ }^{13}$ The indicator is statistically non-significant, suggesting no sample imbalance bias (Wooldridge, 2002). Third, a potential concern is our relatively large sample size since very large samples increase the likelihood of statistically significant coefficients. We take two steps to address this. We re-estimate our models using smaller-sized subsamples (e.g., roughly 165 plants) drawn randomly from industries in the same proportion as the population. The findings remain unchanged. We also conduct out-of-sample comparison tests on multiple subsamples. Regression estimates from particular subsamples are used to predict the dependent variable for other subsamples. $T$-tests show no significant difference in the means of the predicted and actual values.

Fourth, a positive correlation between the outputs of plants in the same firm would add support to the demand volatility thesis, whereas a negative correlation may suggest redistribution within the firm. Hence, we examine the correlation in yearly change in total value of shipments for the three largest plants of each firm in

\footnotetext{
13 Following Wooldridge (2002) and Nijman and Verbeek (1992), we estimated the panel regression and identified plants not included in the estimation, coding the selection indicator for them as 0 (and 1 if included). Then, estimations were run including the lagged indicator in the model. The indicator was statistically nonsignificant and the results were similar to those reported.
} 


\begin{tabular}{|c|c|c|c|c|c|c|}
\hline & \multicolumn{6}{|l|}{ Dependent Variable $=\mathrm{LP}$} \\
\hline & \multicolumn{2}{|c|}{ Cross-sectional models (Year 1999) } & \multicolumn{4}{|c|}{ Panel models (Years 1999-2001) } \\
\hline & (1) & (2) & $\overline{(3)}$ & $(4)$ & (5) & (6) \\
\hline & OLS (without interactions) & OLS (with interactions) & $\mathrm{FE}$ (without interactions) & $\mathrm{FE}$ (with interactions) & HT (without interactions) & HT (with interactions) \\
\hline ITT & $0.001(0.004)$ & $0.001(0.004)$ & & & $-0.018(0.459)$ & $-0.037(0.46)$ \\
\hline ITIP & $0.001(0.003)$ & $0.001(0.003)$ & & & $0.345(0.313)$ & $0.359(0.316)$ \\
\hline Volatility & $-3.915^{* * *}(0.950)$ & $-2.892^{* * *}(1.120)$ & $-0.912^{* * *}(0.181)$ & $-0.975^{* * *}(0.329)$ & $-0.910^{* * *}(0.238)$ & $-0.973^{* *}(0.431)$ \\
\hline ITT $\times$ Volatility & & $-1.046^{* *}(0.490)$ & & $-0.253^{* *}(0.108)$ & & $-0.253^{*}(0.141)$ \\
\hline ITIP $\times$ Volatility & & $0.628^{* *}(0.266)$ & & $0.312^{* * *}(0.098)$ & & $0.312^{* *}(0.128)$ \\
\hline Capital & $0.126^{* * *}(0.013)$ & $0.128^{* * * *}(0.013)$ & $0.030^{*}(0.017)$ & $0.032 *(0.017)$ & $0.031(0.022)$ & $0.033(0.022)$ \\
\hline Materials & $0.557^{* * * *}(0.015)$ & $0.556^{* * *}(0.015)$ & $0.391^{* * * *}(0.008)$ & $0.390^{* * * *}(0.008)$ & $0.391^{* * * *}(0.011)$ & $0.389^{* * * *}(0.011)$ \\
\hline Energy & $-0.005(0.012)$ & $-0.006(0.012)$ & $0.090^{* * * *}(0.009)$ & $0.089 * * *(0.009)$ & $0.090^{* * * *}(0.012)$ & $0.089^{* * * *}(0.012)$ \\
\hline Plant capacity utilization & $0.126^{* * *}(0.038)$ & $0.126^{* * * *}(0.038)$ & $0.180^{* * *}(0.018)$ & $0.181^{* * *}(0.018)$ & $0.180^{* * *}(0.023)$ & $0.181^{* * *}(0.023)$ \\
\hline Size & $-0.698^{* * *}(0.014)$ & $-0.699^{* * *}(0.014)$ & $-0.685^{* * *}(0.016)$ & $-0.686^{* * *}(0.016)$ & $-0.684^{* * *}(0.021)$ & $-0.685^{* * *}(0.021)$ \\
\hline Multiunit & $0.047^{*}(0.028)$ & $0.046 *(0.028)$ & $0.026(0.043)$ & $0.024(0.043)$ & $0.021(0.056)$ & $0.019(0.056)$ \\
\hline Plant age & $-0.002^{*}(0.001)$ & $-0.002 *(0.001)$ & $0.001(0.006)$ & $0.002(0.006)$ & $-0.001(0.006)$ & $-0.001(0.006)$ \\
\hline Industry concentration & $1.176(0.909)$ & $1.106(0.948)$ & $-1.093^{* * *}(0.299)$ & $-1.079^{* * * *}(0.299)$ & $-1.093^{* * *}(0.392)$ & $-1.079^{* * *}(0.392)$ \\
\hline Skill ratio & $-0.023^{* *}(0.011)$ & $-0.024^{* *}(0.011)$ & $-0.060^{* * *}(0.009)$ & $-0.060^{* * *}(0.009)$ & $-0.060^{* * *}(0.012)$ & $-0.061^{* * *}(0.012)$ \\
\hline Share of exports & $-0.020^{* * *}(0.005)$ & $-0.020^{* * * *}(0.005)$ & $-0.017^{* * *}(0.003)$ & $-0.017^{* * *}(0.003)$ & $-0.017^{* * *}(0.004)$ & $-0.017^{* * *}(0.004)$ \\
\hline F-statistic or wald chi-square $\left(\chi^{2}\right)$ & $188.44^{* * *}$ & $183.36^{* * *}$ & $76.36^{* * *}$ & $71.69^{* * *}$ & $3763.32^{* * *}$ & $3734.17^{* * *}$ \\
\hline Prob $>F$ or Prob $>\chi^{2}$ & $p<0.0001$ & $p<0.0001$ & $p<0.0001$ & $p<0.0001$ & $p<0.0001$ & $p<0.0001$ \\
\hline R-square & 0.776 & 0.778 & 0.44 & 0.446 & & \\
\hline Akaike Information Criterion (AIC) & 2539.098 & 2507.962 & -14086.16 & -14248.82 & & \\
\hline Bayesian Information Criterion (BIC) & 2761.726 & 2742.624 & -13993.48 & -14141.89 & & \\
\hline $\begin{array}{l}\chi^{2} / F \text {-test of null that interaction } \\
\text { terms are jointly zero ( } p \text {-value in } \\
\text { parentheses) }\end{array}$ & & $4.66^{* * *}(0.009)$ & & $16.47^{* * *}(0.0000)$ & & $6.79^{* *}(0.033)$ \\
\hline Plants $(n)$ & 3032 & 3032 & 3795 & 3795 & 3795 & 3795 \\
\hline Plant-year observations $(N)$ & & & 9217 & 9217 & 9217 & 9217 \\
\hline $\begin{array}{l}\text { Are instruments valid? (Hausman } \\
\text { test) }\end{array}$ & & & & & Yes & Yes \\
\hline Hausman test statistic & & & & & See note no. 6 & See note no. 6 \\
\hline $\begin{array}{l}\text { Sargan over-identification test } \\
\text { statistic ( } p \text {-value in parentheses) }\end{array}$ & & & & & $2.670(0.263)$ & $2.466(0.292)$ \\
\hline
\end{tabular}

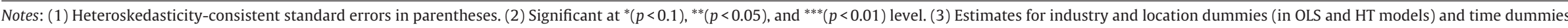

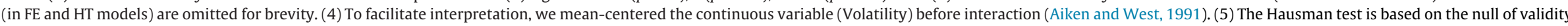

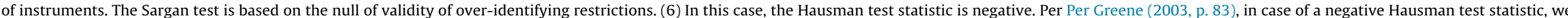
consider it to be zero and "by implication, do not reject the null". 
Table 5

Results of total inventory models.

\begin{tabular}{|c|c|c|c|c|c|c|}
\hline & \multicolumn{6}{|l|}{ Dependent variable $=\mathrm{TI}$} \\
\hline & \multicolumn{2}{|c|}{ Cross-sectional models (Year 1999) } & \multicolumn{4}{|c|}{ Panel models (Year 1999-2001) } \\
\hline & $(1)$ & (2) & (3) & $(4)$ & (5) & (6) \\
\hline & OLS (without interactions) & OLS (with interactions) & FE (without interactions) & FE (with interactions) & HT (without interactions) & HT (with interactions) \\
\hline ITT & $-0.010(0.007)$ & $-0.010(0.007)$ & & & $0.634(0.677)$ & $0.620(0.676)$ \\
\hline ITIP & $-0.0005(0.006)$ & $-0.0001(0.006)$ & & & $-0.006(0.350)$ & $-0.001(0.347)$ \\
\hline Volatility & $3.922 * * *(1.454)$ & $3.177^{*}(1.857)$ & $6.429^{* * * *}(0.735)$ & $5.634^{* * *}(1.141)$ & $6.499^{* * *}(0.663)$ & $5.113^{* * *}(1.015)$ \\
\hline ITT $\times$ Volatility & & $1.642 * *(0.669)$ & & $1.411^{* * *}(0.344)$ & & $1.288^{* * *}(0.304)$ \\
\hline ITIP $\times$ Volatility & & $-1.488^{* * *}(0.546)$ & & $-1.039^{* * *}(0.313)$ & & $-0.690^{* *}(0.277)$ \\
\hline Capital & $0.029(0.020)$ & $0.027(0.020)$ & $-0.168^{* * *}(0.059)$ & $-0.172^{* * *}(0.059)$ & $-0.100^{* *}(0.044)$ & $-0.099^{* *}(0.044)$ \\
\hline Materials & $-0.121^{* * *}(0.021)$ & $-0.121^{* * *}(0.021)$ & $0.009(0.020)$ & $0.009(0.019)$ & $0.006(0.019)$ & $0.005(0.019)$ \\
\hline Plant capacity utilization & $0.387^{* * * *}(0.072)$ & $0.394^{* * * *}(0.071)$ & $-0.033(0.039)$ & $-0.034(0.039)$ & $-0.048(0.036)$ & $-0.050(0.037)$ \\
\hline Size & $0.054^{* *}(0.026)$ & $0.055^{* *}(0.026)$ & $0.105^{* * *}(0.037)$ & $0.110^{* * * *}(0.037)$ & $0.056 *(0.033)$ & $0.061^{*}(0.033)$ \\
\hline Multiunit & $0.016(0.058)$ & $0.017(0.058)$ & $-0.216 *(0.119)$ & $-0.212^{*}(0.119)$ & $-0.128 *(0.105)$ & $-0.124 *(0.106)$ \\
\hline Plant age & $0.008^{* * *}(0.002)$ & $0.008^{* * *}(0.002)$ & $-0.005(0.013)$ & $-0.005(0.013)$ & $-0.003(0.011)$ & $-0.003(0.011)$ \\
\hline Output growth & $-0.211^{* * *}(0.061)$ & $-0.196^{* * *}(0.056)$ & $-0.401^{* * *}(0.018)$ & $-0.395^{* * *}(0.018)$ & $-0.377^{* * *}(0.018)$ & $-0.375^{* * *}(0.018)$ \\
\hline Number of products & $0.010(0.009)$ & $0.011(0.009)$ & $0.004(0.011)$ & $0.005(0.011)$ & $0.004(0.010)$ & $0.005(0.010)$ \\
\hline Industry Concentration & $-0.628(1.395)$ & $-0.522(1.389)$ & $0.781(0.850)$ & $0.693(0.847)$ & $-0.096(0.837)$ & $-0.174(0.838)$ \\
\hline F-statistic or wald chi-square $\left(\chi^{2}\right)$ & $15.87^{* * * *}$ & $15.53^{* * * *}$ & $79.47^{* * * *}$ & $69.34^{* * * *}$ & $1011.45^{* * *}$ & $1032.45^{* * *}$ \\
\hline Prob $>F$ or Prob $>\chi^{2}$ & $p<0.0001$ & $p<0.0001$ & $p<0.0001$ & $p<0.0001$ & $p<0.0001$ & $p<0.0001$ \\
\hline R-square & 0.162 & 0.17 & 0.235 & 0.241 & & \\
\hline Akaike Information Criterion (AIC) & 7772.656 & 7741.909 & -4914.93 & -4953.61 & & \\
\hline Bayesian Information Criterion (BIC) & 7992.858 & 7974.345 & -4833.819 & -4858.981 & & \\
\hline $\begin{array}{l}\chi^{2} / F \text {-test of null that interaction } \\
\text { terms are jointly zero ( } p \text {-value in } \\
\text { parentheses) }\end{array}$ & & $4.76^{* * *}(0.009)$ & & $10.58^{* * * *}(0.0000)$ & & $19.16^{* * *}(0.0001)$ \\
\hline Plants $(n)$ & 3350 & 3350 & 3521 & 3521 & 3408 & 3408 \\
\hline Plant-year observations $(N)$ & & & 6369 & 6369 & 6256 & 6256 \\
\hline $\begin{array}{l}\text { Are instruments valid? (Hausman } \\
\text { test) }\end{array}$ & & & & & Yes & Yes \\
\hline $\begin{array}{l}\text { Hausman test statistic ( } p \text {-value in } \\
\text { parentheses) }\end{array}$ & & & & & $0.01(1.000)$ & $0.01(1.000)$ \\
\hline $\begin{array}{l}\text { Sargan over-identification test } \\
\text { statistic ( } p \text {-value in parentheses) }\end{array}$ & & & & & $0.281(0.596)$ & $0.34(0.56)$ \\
\hline
\end{tabular}

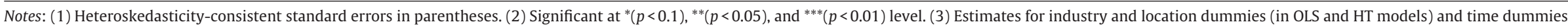

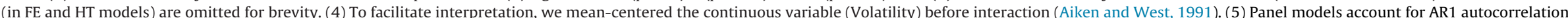
(6) The Hausman test is based on the null of validity of instruments. The Sargan test is based on the null of validity of over-identifying restrictions. 
Table 6

Results of exploratory analysis: inventory disaggregation.

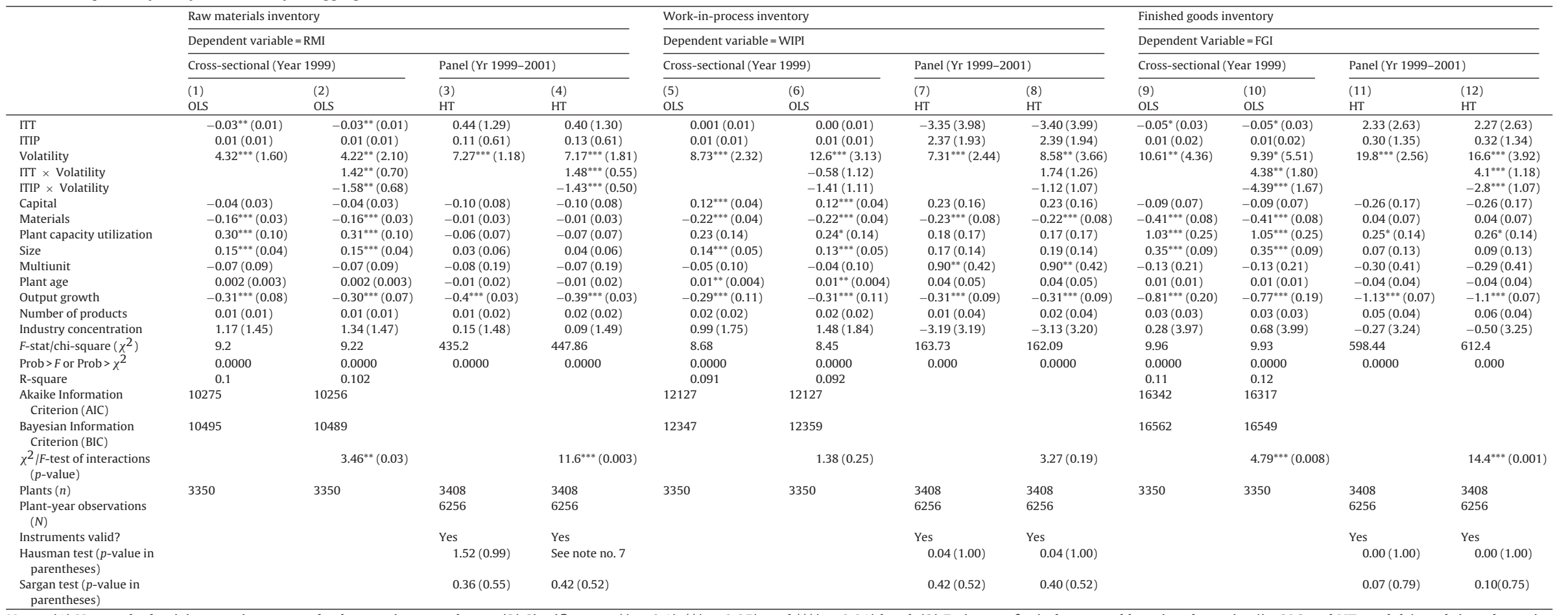

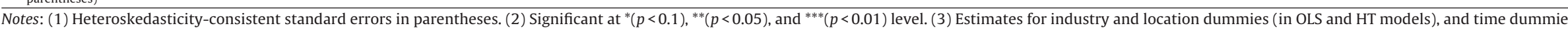

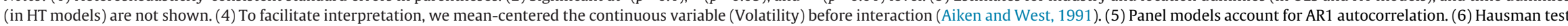

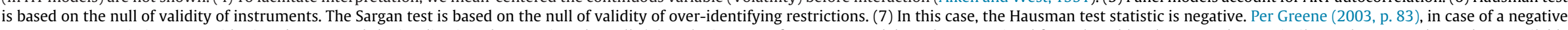

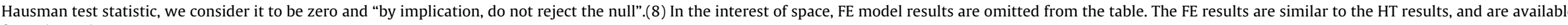
from the authors upon request. 
Table 7

Summary of findings.

\begin{tabular}{|c|c|c|}
\hline Hypothesis (abbreviated) & Support? & \\
\hline H1a & ITT is positively associated with labor productivity & No \\
\hline $\mathrm{H} 1 \mathrm{~b}$ & ITT is positively associated with inventory turnover & No \\
\hline $\mathrm{H} 2 \mathrm{a}$ & ITIP is positively associated with labor productivity & No \\
\hline $\mathrm{H} 2 \mathrm{~b}$ & ITIP is positively associated with inventory turnover & No \\
\hline Н3а & (ITT $\times$ Volatility) is negatively associated with labor productivity & Yes \\
\hline $\mathrm{H} 3 \mathrm{~b}$ & (ITT $\times$ Volatility) is negatively associated with inventory turnover & Yes \\
\hline $\mathrm{H} 4 \mathrm{a}$ & $($ ITIP $\times$ Volatility) is positively associated with labor productivity & Yes \\
\hline $\mathrm{H} 4 \mathrm{~b}$ & (ITIP $\times$ Volatility) is positively associated with inventory turnover & Yes \\
\hline H5a (exploratory) & (ITT $\times$ Volatility) is negatively associated with RMI turnover and FGI turnover & Yes \\
\hline $\mathrm{H} 5 \mathrm{~b}$ (exploratory) & (ITIP $\times$ Volatility) is positively associated with RMI turnover and FGI turnover & Yes \\
\hline
\end{tabular}

the sample. The correlation coefficients are positive and significant, further supporting our primary thesis. Fifth, we performed several diagnostic checks to ascertain the stability of results. We tested for normality of residuals, multicollinearity, outliers, and influential observations, and found no problems or violations of assumptions (Belsley et al., 1980; Greene, 2003). Last, common method bias is not of concern as the variables have different sources, the performance variables are accounting (not perceptual) data, and the IT variables are generally unambiguous ('use' versus 'do not use') (Podsakoff et al., 2003).

\section{Discussion}

\subsection{Findings}

Our main finding, consistent across a variety of estimation approaches and two performance metrics, is that demand volatility is a significant moderator of the link between IT and operational performance in the context of supply chains. Consistent with our hypotheses (Table 7), the IT-performance link is differently moderated by demand volatility depending on whether IT is employed for transaction purposes or used for a higher level of collaboration through information partnering. Our thesis finds strong empirical support when value is captured in terms of labor productivity and (total) inventory performance. Our findings suggest that using interorganizational IT for collaborating with supply chain partners provides firms with IT-enabled flexibility and dynamic capabilities to adapt to volatile demand conditions; whereas, firms that use interorganizational IT at a transactional level are hindered by the negative impacts of volatility. Moreover, our exploratory analysis results suggest that the moderating role of demand volatility is different, based on the stage of manufacturing where value (inventory performance) is measured. These results suggest that, in volatile conditions, in-bound processes and out-bound processes are where firms can gain maximum benefit from interorganizational IT-based collaboration in the supply chain. Taken together, our findings uncover the contextual value of IT-enabled interorganizational business processes to support OM processes under differing demand volatility conditions.

The non-significant main effect of ITIP (information sharing), although unexpected, has precedence in the literature. For example, in a study of divisions of manufacturing companies in the food and packaged goods industry in 1998, Kulp et al. (2004) found no direct positive association between information sharing and subjective performance measures, barring sharing of store inventory information. Similarly, the non-significant main effect of ITT, though unsupportive of $\mathrm{H} 1$, is consistent with a study of firms in the automotive, computers and electronics sector. In that study (Devaraj et al., 2007, p. 1212), “... .findings indicated that e-business capabilities, by themselves, do not directly impact operational performance."

A potential interpretation of the non-significant main effect and negative interaction of ITT and VOL is that in highly volatile conditions, using rather than not using ITT leads to worse performance. However, our results can be explained by a number of alternate plausible theories. For example, the plants in our study may not have developed operational practices or other organizational, social, and human resource capabilities that complement ITT and facilitate maximum returns to ITT investment. To achieve adaptability in complex environments, this includes developing organizational capabilities for business process flexibility and dynamic reconfiguration of human resources (Melville et al. 2004). ${ }^{14}$

\subsection{Theoretical contributions}

Our results are new to the literature and constitute two primary theoretical contributions. The first contribution lies in differentiating how IT is used or applied (for transactions and for collaborating/information partnering) with supply chain partners, and in uncovering the moderating role of demand volatility on the link between specific types of IT use and operational performance. This finding complements arguments in the OM literature that specific manufacturing capabilities and flexibilities are required in dynamic conditions (Anand and Ward, 2004; Germain et al., 2008; Sawhney, 2013; Wong et al., 2011). Our cross-examination of the type of IT use and demand volatility represents a contribution to "interdisciplinary theoretical understanding" of IT-based interorganizational capabilities and demand volatility in the supply chain context, in the spirit of calls for research in the literature (Rai et al., 2006, pp. 239-240; Venkatesh, 2010). Our study enhances theoretical understanding of the moderating role of demand volatility on the IT-performance relationships, and may help explain some of the related mixed findings in OM and IS research (Table 1). More specifically, our study suggests that ITIP provides dynamic capabilities, and the study reinforces the need to carefully consider how IT is used (Devaraj and Kohli, 2003) in interorganizational supply chain processes, to help tease out the impact of demand volatility on the IT-performance relationship. Thus, our study contributes to developing theory of "contingencies under which digitization is more or less successful," and a better understanding of the match of "IT-based capabilities with various conditions under which digitization is more or less successful in creating business value" (as Kohli and Grover (2008, p. 29,32) call for) in supply chain contexts. Our study also reinforces the need for greater transparency of information and IT-enabled collaboration among firms in a digital world

\footnotetext{
14 Plants may also not have reached a level of IT infrastructure sophistication to benefit from ITT in volatile conditions (Zhu and Kraemer, 2002). For example, if their Enterprise Resource Planning (ERP) systems or business process IT systems were inflexible or underdeveloped to leverage ITT, then volatility would have a more severe impact on ITT value. Finally, ITT may trigger automatic ordering to an extent that, in volatile conditions, such excess automation may hinder flexibility and performance (Suarez et al., 1996).
} 
(Bennis, 2013; Granados and Gupta, 2013; Mithas et al., 2013; Setia et al., 2013).

Second, whereas extant OM and IS research related to the moderating role of environmental conditions has generally considered the firm as the analysis unit, our research contributes to the literature by exploring inventory impacts at a finer level, at various stages of manufacturing (inbound, in-process, outbound). Although the nuances of RMI, FGI, and WIPI have received attention in the OM literature (e.g., Cachon and Olivares, 2010; Lieberman et al., 1999), research at the nexus of IT and these forms of inventory is limited, barring few exceptions (Dehning et al., 2007). Our study suggests that the moderating role of volatility on IT value is seen at the outward interfaces of the plant. Theoretically, this enhances understanding of the contingent value of IT use with suppliers and customers, and the stages of manufacturing at which the contingent value is manifested. In sum, this study contributes to scholarly understanding of the contextual nature of the "symbiotic relationship" between OM and specific uses of IS in the supply chain (Venkatesh, 2010).

\subsection{Practical contributions}

Inter-organizational processes and supply chain partnerships are occurring more widely across industries. Apple Inc., for example, focuses on iPhone design while its partners focus on iPhone manufacturing. In several industries, innovation networks are beginning to take hold as firms move from an internally focused innovation model to a partnership model. Our study illuminates IT's role in these evolving supply chains, in particular, by identifying purposes of IT application that are more appropriate under highly volatile demand.

Searching for synergies of IT with the environment or market contexts is an important managerial concern. Our results enhance managerial understanding of the performance implications of IT use, when demand is stable versus volatile. Our study suggests that using IT for information partnering with supply chain partners is more likely to provide firms with agility for coping with challenging business environments characterized by high demand volatility. Our exploratory analysis suggests that inbound and outbound inventory are areas that can benefit the most from IT investment in volatile demand conditions, suggesting that future studies examine coupling between plants and suppliers and customers to test underlying mechanisms.

Our study suggests how manufacturers can maximize returns to IT investment. An important implication for senior executives is that careful management of IT deployment and use according to environmental conditions is essential for performance. Failure to account for the environment, including demand volatility, can lead to unrealizable expectations of IT's impact. Our study helps managers better understand the impacts of types of IT use, given the firm's market context. Supply chain managers facing turbulent conditions might leverage emerging IT like social media to provide information partnering capabilities for performance improvement. Our study suggests that investments in such uses of IT for collaboration may be more beneficial in volatile conditions than transactional IT investments. In sum, our results add to the comprehensive picture of contingent factors that firms must consider when making IT investments.

\subsection{Limitations and future research}

Our study should be viewed in light of its limitations, which can be starting points for future research. First, because the ASM is weighted toward large plants and we do not adjust for non-respondents to the CNUS, our results may not generalize to non-respondents or plants of all sizes. However, CNUS respondents account for a substantial share (roughly 50 to 60\%) of U.S. manufacturing employment and output (Atrostic and Nguyen, 2005). Second, though our three-year panel (used for robustness) is reasonable and consistent with similar approaches in prior studies (Black and Lynch, 2001; Bresnahan et al., 2002; Brynjolfsson et al., 2002; Joshi et al., 2010; Ramirez et al., 2010), future research can use longer time series data. Third, our binary IT measures are based on use, a benefit over measures that just capture the presence of IT. But this may also be a limitation as we do not have more granular metrics of usage (Devaraj and Kohli, 2003). Still, our binary metrics can be viewed as a reliable proxy. Although prior IT value research has employed binary measures of IT (e.g., Banker et al., 2006; Heim and Peng, 2010), future work can use more refined measures. Fourth, our measure of volatility is on an annual basis. Future work can use more fine-grained measures based on timeframes customized for a firm's context. Last, demand volatility may partly be a result of internal process efficiency rather than changes in customer demand. Nonetheless, demand volatility is an important factor influencing supply chains (Lee et al., 2004).

Our study can motivate much future research at the intersection of IS and OM. First, the underlying mechanisms driving the moderating role of demand volatility need to be empirically studied. Future research can look at more complex interrelations and use alternative methods (e.g., structural modeling, case studies) to examine key OM phenomena underlying the differential impact of demand volatility on IT value. Second, IS and OM researchers can examine how IS used for supply chain collaboration (e.g., social media) may complement or substitute manufacturing flexibility in volatile demand conditions. Third, whereas we focused on demand volatility, future work can investigate IT value under volatile supply conditions (Rai et al., 2006). Fourth, though we examined two performance measures, future research can study whether our findings hold for other measures such as innovation or customer service, incorporating potential tradeoffs across the measures. Fifth, as discussed earlier, our IT variables pertain to how IT is used and are not confined to specific technologies. Though we do not expect significant changes in results when technologies used are varied, future work can study modern technologies like business analytics or social media to confirm and refine our findings. Last, our empirical context, limited to U.S. manufacturing, enhances internal validity but hinders generalizability. Extending this study to service sectors or other countries may yield new insights.

\subsection{Concluding remarks}

Analyses such as those described herein can serve as a platform for cross-pollination of research from OM and IT. Each literature provides valuable and complementary perspectives. To the extent that IT is a moderator, mediator, or influencing factor for supply chain phenomena under different environmental conditions, we can expect to make progress in the joint research agenda. As an example, this study addressed what IT is appropriate in volatile demand conditions. Future studies can examine demand volatility when long lead times are required or can compare industries to see if different types of IT, IT-enabled capabilities, and agilities are necessary in different supply chain conditions. Future research can also address what IT capabilities and agilities are appropriate to address supply volatility (e.g., strikes, earthquakes). A research agenda like this requires the combined efforts of both OM and IT researchers.

\section{Acknowledgments}

We thank the Guest Editor, Dr. Viswanath Venkatesh and the reviewers for their helpful comments, suggestions and insights 
during the review process of this paper; their inputs significantly improved this paper. We thank the U.S. Census Bureau for providing us access to the datasets. We are grateful to Clint Carter, Dr. Margaret Levenstein, Arnold Reznek, and all staff at the Michigan Census Research Data Center and the U.S. Census Bureau for their administrative assistance and support. We gratefully acknowledge the inputs of participants at Workshop of Information Systems and Economics (WISE) 2011 and the U.S.-Canadian Census Research Data Center Conference 2009 where earlier versions of this paper were presented. We thank Dr. M.S. Krishnan, Dr. Dennis Severance, Dr. Ravi Anupindi, and seminar participants of the Stephen M. Ross School of Business at the University of Michigan for helpful comments on earlier versions of this paper. Any errors that might remain in this paper are ours alone.

\section{Appendix A. Details on census datasets}

The CM is conducted every five years and the ASM is conducted in every non-CM year. The ASM sample reflects USCB's goal of a representative sample: roughly 52,000 selected from roughly 366,000 plants in CM 1997; of these, about 16,600 selected with certainty based on size and importance in industry, and about 35,400 selected with probabilities proportional to size and importance (U.S. Census Bureau, 2001). CNUS (83\% response rate) was supplemental to the ASM 1999 (Atrostic and Nguyen, 2005). SPCU covers roughly 17,000 plants chosen with probabilities proportional to the value of shipments in each industry (U.S. Census Bureau, 2010b).

\section{Appendix B. Summary statistics and correlations for the inventory model}

1999-2001. Even if disruptive innovations took place during this time, it is unlikely that many firms, even early adopters, were able to invest in, learn, and implement such new technologies in the short time period. Fourth, extension of one-time data in subsequent years is not without precedent (Black and Lynch, 2001; Bresnahan et al., 2002; Brynjolfsson et al., 2002; Joshi et al., 2010; Ramirez et al., 2010). These studies show that IT and organizational factors involved in a system of change are complements; these system factors as a whole evolve simultaneously. Indeed, research suggests that impacts from such systems evolve over a 5- to 7-year timeframe (Brynjolfsson and Hitt, 2003; Brynjolfsson et al., 2002). Assumption of continued use after single reporting is consistent with prior IS research (Joshi et al., 2010, p. 481) who "assume that if an IT application was reported in use at a specific year, then it would be used in future years". In sum, while we do not have exact measures of IT use in 2000 and 2001, we argue conservatively that the extended measures are related to the actual measures; and our estimated signs and significances are robust to data extension, given no observed systematic changes in the period.

\section{Appendix D. Details on panel estimation models}

We considered fixed-effects (FE) and random-effects (RE) panel models (Greene, 2003). Hausman tests indicated that RE model is inconsistent whereas the FE model, though inefficient, is consistent (Hausman, 1978). Hence we use FE models with White's correction (White, 1980) and year dummies to respectively account for heteroskedasticity and year-specific heterogeneity.

\begin{tabular}{|c|c|c|c|c|c|c|c|c|c|c|c|c|c|c|c|c|c|c|}
\hline & Variables & Mean & SD & 1 & 2 & 3 & 4 & 5 & 6 & 7 & 8 & 9 & 10 & 11 & 12 & 13 & 14 & 15 \\
\hline 1 & TI & -2.29 & 0.83 & 1 & & & & & & & & & & & & & & \\
\hline 2 & RMI & -3.54 & 1.17 & $0.58^{*}$ & 1 & & & & & & & & & & & & & \\
\hline 3 & WIPI & -4.35 & 1.58 & $0.52^{*}$ & $0.15^{*}$ & 1 & & & & & & & & & & & & \\
\hline 4 & FGI & -3.61 & 1.53 & $0.69^{*}$ & $0.21^{*}$ & $0.18^{*}$ & 1 & & & & & & & & & & & \\
\hline 5 & ITT & 2.58 & 2.05 & -0.01 & $-0.03^{*}$ & 0.03 & -0.02 & 1 & & & & & & & & & & \\
\hline 6 & ITIP & 2.10 & 2.36 & 0.00 & 0.01 & $0.06^{*}$ & -0.03 & $0.47^{*}$ & 1 & & & & & & & & & \\
\hline 7 & Volatility & 0.03 & 0.01 & $0.14^{*}$ & $0.13^{*}$ & $0.06^{*}$ & $0.05^{*}$ & -0.01 & -0.00 & 1 & & & & & & & & \\
\hline 8 & Capital & 10.2 & 1.35 & $-0.10^{*}$ & $-0.11^{*}$ & -0.03 & $-0.07^{*}$ & $0.15^{*}$ & $0.10^{*}$ & $-0.08^{*}$ & 1 & & & & & & & \\
\hline 9 & Materials & 10.49 & 1.34 & $-0.21^{*}$ & $-0.19 *$ & $-0.14^{*}$ & $-0.12^{*}$ & $0.11^{*}$ & $0.09 *$ & $-0.18^{*}$ & $0.74^{*}$ & 1 & & & & & & \\
\hline 10 & PCU & 0.68 & 0.20 & $0.17^{*}$ & $0.12^{*}$ & $0.10^{*}$ & $0.09^{*}$ & $-0.05^{*}$ & $-0.08^{*}$ & $-0.17^{*}$ & $0.19^{*}$ & $0.22 *$ & 1 & & & & & \\
\hline 11 & Size & 5.86 & 0.94 & $-0.09^{*}$ & $-0.07^{*}$ & $0.05^{*}$ & $-0.08^{*}$ & 0.19* & $0.18^{*}$ & $-0.17^{*}$ & $0.70^{*}$ & $0.70^{*}$ & $0.14^{*}$ & 1 & & & & \\
\hline 12 & Multiunit & 0.93 & 0.24 & -0.02 & $-0.04^{*}$ & -0.03 & -0.01 & $0.04^{*}$ & 0.01 & -0.01 & $0.22^{*}$ & $0.19^{*}$ & $0.03^{*}$ & $0.16^{*}$ & 1 & & & \\
\hline 13 & Plant age & 24.8 & 6.37 & 0.06* & -0.00 & $0.05^{*}$ & 0.06* & $0.07^{*}$ & $0.06^{*}$ & $-0.05^{*}$ & $0.15^{*}$ & $0.09^{*}$ & 0.02 & $0.14^{*}$ & $0.07^{*}$ & 1 & & \\
\hline 14 & GROW & -0.09 & 0.31 & $-0.16^{*}$ & $-0.14^{*}$ & $-0.11^{*}$ & $-0.06^{*}$ & $-0.05^{*}$ & $-0.06^{*}$ & $-0.38^{*}$ & -0.03 & $0.13^{*}$ & $0.21^{*}$ & $0.04^{*}$ & $-0.03^{*}$ & $-0.04^{*}$ & 1 & \\
\hline 15 & Number of products & 2.09 & 1.62 & -0.02 & $-0.03^{*}$ & 0.03 & -0.00 & $0.04^{*}$ & 0.01 & $-0.08^{*}$ & $0.21^{*}$ & $0.22 *$ & 0.02 & $0.23^{*}$ & $0.05^{*}$ & $0.14^{*}$ & $0.05^{*}$ & 1 \\
\hline 16 & Concentration & 0.06 & 0.05 & 0.01 & 0.00 & $0.06^{*}$ & $-0.08^{*}$ & $0.06^{*}$ & $0.04^{*}$ & $0.05^{*}$ & $0.09^{*}$ & $0.11^{*}$ & -0.00 & $0.12^{*}$ & $0.04^{*}$ & -0.03 & $-0.06^{*}$ & 0.00 \\
\hline
\end{tabular}

Notes: (1) * Denotes significance at $\alpha=0.05$. (2) The minimum and maximum values are not reported because the USCB prohibits their disclosure. (3) year $=1999 ; n=3350$.

\section{Appendix C. Extension of ITT and ITIP for panel estimations}

Consistent with research in economics and IS (Black and Lynch, 2001; Brynjolfsson et al., 2002; Bresnahan et al., 2002; Joshi et al., 2010; Ramirez et al., 2010), we extend the CNUS data by assuming that IT usage reported in CNUS 1999 is the same in 2000 and 2001. This extension is reasonable for many reasons. First, e-business systems are important investments requiring time for planning and implementation. Consistent with Bresnahan et al. (2002), while we do not know the exact level of IT use in 1999-2001, the 1999 measures reflect IT use during that time frame. Second, ITT and ITIP comprise multiple measures: nine for ITT and twelve for ITIP. It is unlikely that over the short span of extension, a plant's use of IT would change significantly over all or many of these measures. Also, our findings are robust to the exclusion of some measures of ITT and ITIP. So even if some measures changed in 2000/2001, it would not largely impact our results. Third, beyond quantity usage changes in IT, no large quality changes in IT took place in
FE does not estimate time-invariant ITT and ITIP; we use Hausman-Taylor models (HT) that permit their estimation without the strong assumption (of RE) that all variables are uncorrelated with plant effects (Hausman and Taylor, 1981).Another advantage of HT models is that external instruments are not needed, but are instead constructed from inside the model, based partly on timevariant variables considered exogenous to (uncorrelated with) unobserved plant effects, and partly on deviation from group means of time-variant variables considered endogenous to (i.e., correlated with) plant effects; model consistency, instrument validity, and theoretical choice of exogenous variables are tested by Hausman test (Greene, 2003). Also, HT is more efficient than FE(Hausman and Taylor, 1981). HT thus test $\mathrm{H} 1-\mathrm{H} 2$, and provide robustness with FE for $\mathrm{H} 3-\mathrm{H} 5$.

For identification, the HT model requires at least as many exogenous time-variant variables as endogenous time-invariant variables (Greene, 2003). As we have two potentially endogenous 
time-invariant variables (ITT, ITIP), ${ }^{15}$ we need at least two timevariant exogenous variables. The two best candidates are CONC and plant AGE, for following reasons. First, CONC is likely driven by external factors like customers and regulators, and so is unlikely correlated with plant unobserved effects. This is consistent with research that treats market characteristics as exogenous to firm effects in HT models (Pfaffermayr, 1999). Second, as plants age, time-invariant effects, by definition, do not change. Also, as average AGE in our samples is roughly 25 years, and ASM is weighted toward large and important plants (U.S. Census Bureau, 2010a), survival is unlikely a key issue for the plants. Further, as unobserved effects cannot alter the course of time, feedback from effects to AGE is unlikely. Hence, AGE is unlikely correlated with unobserved plant effects. Thus, consistent with studies that treat firm age as exogenous to firm unobserved effects in HT models (e.g., Engberg et al., 2004), we treat AGE as exogenous to plant effects.

Nonetheless, we acknowledge the challenge of identifying exogenous variables based on theory alone. ${ }^{16}$ Hence we test the validity of instruments resulting from the use of particular variables as exogenous. The validity of instruments and choice of doubly exogenous (exogenous to individual effects and idiosyncratic error term) or singly exogenous (exogenous to only the error term) variables can be tested by the Hausman test; a non-significant test statistic indicates HT model consistency (Hausman and Taylor, 1981). The tests indicated instrument validity, supporting our choice of AGE and CONC. As the time dummies are exogenous and time-variant by definition, we have more time-variant exogenous variables than are needed. Hence, we ran Sargan overidentification tests; the non-significant statistics suggested instrument validity and model appropriateness (Sargan, 1958). Last, as is common practice, we estimate the inventory panel models controlling for autocorrelation. Specifically, we used FE models accounting for AR(1) autocorrelation (Rumyantsev and Netessine, 2007), and we followed the procedures specified in Boulding and Christen (2003) to account for AR(1) autocorrelation in HT models. ${ }^{17}$

\section{References}

Aiken, L., West, S., 1991. Multiple Regression: Testing and Interpreting Interactions. SAGE Publications, Newbury Park, CA.

Allen, B., Boynton, A., 1991. Information architecture: in search of efficient flexibility. MIS Quarterly 15 (4), 435-445.

Anand, G., Ward, P., 2004. Fit, flexibility and performance in manufacturing: coping with dynamic environments. Production and Operations Management 13 (4), 369-385.

Anderson, E., Fine, C., Parker, G., 2000. Upstream volatility in the supply chain: the machine tool industry as a case study. Production and Operations Management 9 (3), 239-261.

Aral, S., Weill, P., 2007. IT assets, organizational capabilities, and firm performance: how resource allocations and organizational differences explain performance variation. Organization Science 18 (5), 763-780

Atrostic, B., Nguyen, S., 2005. IT and productivity in U.S. manufacturing: do computer networks matter? Economic Inquiry 43 (3), 493-506.

Banker, R., Bardhan, I., Chang, H., Lin, S., 2006. Plant information systems, manufacturing capabilities, and plant performance. MIS Quarterly 30 (2), 315-337.

Belsley, D., Kuh, E., Welsch, R., 1980. Regression Diagnostics: Identifying Influential Data and Sources of Collinearity. John Wiley and Sons, New York.

Berman, E., Bound, J., Griliches, Z., 1994. Changes in the demand for skilled labor within U.S. manufacturing: evidence from the annual survey of manufacturers. The Quarterly Journal of Economics 109 (2), 367-397.

Bennis, W., 2013. Leadership in a digital world: embracing transparency and adaptive capacity. MIS Quarterly 37 (2), 635-636.

\footnotetext{
${ }^{15}$ For example, use of IT may be correlated with unobserved plant-level characteristics such as plant manager capabilities.

${ }^{16}$ We considered PCU a next-best exogenous candidate as PCU is partly determined by industry factors. Results were similar.

17 We thank an anonymous reviewer for suggesting to account for autocorrelation. AR(1) transformation reduces the sample size.
}

Bharadwaj, A., Bharadwaj, S., Konsynski, B., 1999. Information technology effects on firm performance as measured by Tobin's q. Management Science 45 (7), 1008-1024.

Bharadwaj, A., El Sawy, O., Pavlou, P., Venkatraman, N., 2013. Digital business strategy: toward a next generation of insights. MIS Quarterly 37 (2), 471-482.

Bischoff, C., Kokkelenberg, E., 1987. Capacity utilization and depreciation-in-use (USA). Applied Economics 19 (8), 995-1007.

Black, S., Lynch, L., 2001. How to compete: the impact of workplace practices and information technology on productivity. The Review of Economics and Statistics 83 (3), 434-445

Boulding, W., Christen, M., 2003. Sustainable pioneering advantage? Profit implications of market entry order. Marketing Science 22 (3), 371-392.

Bourgeois, L., Eisenhardt, K., 1988. Strategic decision-processes in high-velocity environments -4 cases in the microcomputer industry. Management Science 34 (7), 816-835.

Bourland, K., Powell, S., Pyke, D., 1996. Exploiting timely demand information to reduce inventories. European Journal of Operational Research 92 (2) 239-253.

Bresnahan, T., Brynjolfsson, E., Hitt, L., 2002. Information technology, workplace organization, and the demand for skilled labor: firm-level evidence. The Quarterly Journal of Economics 117 (1), 339-376.

Brush, T., Karnani, A., 1996. Impact of plant size and focus on productivity: an empirical study. Management Science 42 (7), 1065-1081.

Brynjolfsson, E., Hitt, L., 2003. Computing productivity: firm-level evidence. The Review of Economics and Statistics 85 (4), 793-808.

Brynjolfsson, E., Hitt, L., Yang, S., 2002. Intangible assets: computers and organizational capital. Brookings Papers on Economic Activity 1, 137-181.

Cachon, G., Fisher, M., 2000. Supply chain inventory management and the value of shared information. Management Science 46 (8), 1032-1048.

Cachon, G., Olivares, M., 2010. Drivers of finished-goods inventory in the U.S. automobile industry. Management Science 56 (1), 202-216.

Callen, J., Fader, C., Krinsky, I., 2000. Just-in-time: a cross-sectional plant analysis. International Journal of Production Economics 63 (3), 277-301.

Capkun, V., Hameri, A., Weiss, L., 2009. On the relationship between inventory and financial performance in manufacturing companies. International Journal of Operations Production Management 29 (8), 789-806.

Chen, F., 1998. Echelon reorder points, installation reorder points, and the value of centralized demand information. Management Science 44 (12), $221-234$.

Dehning, B., Richardson, V., Zmud, R., 2007. The financial performance effects of IT-based supply chain management systems in manufacturing firms. Journal of Operations Management 25 (4), 806-824.

Devaraj, S., Kohli, R., 2003. Performance impacts of information technology: is actual usage the missing link? Management Science 49 (3), 273-289.

Devaraj, S., Krajewski, L., Wei, J., 2007. Impact of ebusiness technologies on operational performance: the role of production information integration in the supply chain. Journal of Operations Management 25 (6), 1199-1216.

Dewan, S., Shi, C., Gurbaxani, V., 2007. Investigating the risk-return relationship of information technology investment: firm-level empirical analysis. Management Science 53 (12), 1829-1842.

Diamantopoulos, A., Winklhofer, H., 2001. Index construction with formative indicators: an alternative to scale development. Journal of Marketing Research 38 (2), 269-277.

Dong, S., Xu, S., Zhu, K., 2009. Information technology in supply chains: the value of IT-enabled resources under competition. Information Systems Research 20 (1), 18-32.

Engberg, J., Wholey, D., Feldman, R., Christianson, J., 2004. The effect of mergers on firms' costs: evidence from the HMO industry. The Quarterly Review of Economics and Finance 44 (4), 574-600.

Fynes, B., De Búrca, S., Marshall, D., 2004. Environmental uncertainty, supply chain relationship quality and performance. Journal of Purchasing and Supply Management 10 (4-5), 179-190.

Gavirneni, S., Kapuscinski, R., Tayur, S., 1999. Value of information in capacitated supply chains. Management Science 45 (1), 16-24.

Germain, R., Claycomb, C., Cornelia, D., 2008. Supply chain variability, organizational structure, and performance: the moderating effect of demand unpredictability. Journal of Operations Management 26 (5), 557-570.

Gosain, S., Malhotra, A., El Sawy, O., 2005. Coordinating for flexibility in e-business supply chains. Journal of Management Information Systems 21 (3), 7-45.

Granados, N., Gupta, A., 2013. Transparency strategy: competing with information in a digital world. MIS Quarterly 37 (2), 637-641.

Greene, W., 2003. Econometric Analysis, Fifth ed. Prentice Hall, Upper Saddle River, NJ.

Gunasekaran, A., Patel, C., Tirtiroglu, E., 2001. Performance measures and metrics in a supply chain environment. International Journal of Operations Production Management 21 (1/2), 71-87.

Hausman, J., Taylor, W., 1981. Panel data and unobservable individual effects. Econometrica 49 (6), 1377-1398.

Hausman, J., 1978. Specification tests in econometrics. Econometrica 46 (6), $1251-1271$

Heim, G., Peng, D., 2010. The impact of information technology use on plant structure, practices, and performance: an Exploratory study. Journal of Operations Management 28 (2), 144-162. 
Henderson, J., Venkatraman, N., 1993. Strategic alignment-leveraging information technology for transforming organizations. IBM Systems Journal 32 (1), 4-16.

Inman, R., Sale, R., Green, K., Whitten, D., 2011. Agile manufacturing: relation to JIT, operational performance and firm performance. Journal of Operations Management 29 (4), 343-355.

Joshi, K., Chi, L., Datta, A., Han, S., 2010. Changing the competitive landscape: continuous innovation through IT-enabled knowledge capabilities. Information Systems Research 21 (3), 472-495.

Knoll, K., Jarvenpaa, S., 1994. Information technology alignment or 'fit' in highly turbulent environment: the concept of flexibility. ACM SIGCPR Computer Personnel. pp. 1-14.

Kobelsky, K., Hunter, S., Richardson, V., 2008. Information technology, contextual factors and the volatility of firm performance. International Journal of Accounting Information Systems 9 (3), 154-174.

Kohli, R., Grover, V., 2008. Business value of IT: an essay on expanding research directions to keep up with the times. Journal of the Association for Information Systems 9 (1), 23-39.

Kolias, G., Dimelis, S., Filios, V., 2011. An empirical analysis of inventory turnover behaviour in Greek retail sector: 2000-2005. International Journal of Production Economics 133 (1), 143-153.

Koufteros, X., Vonderembse, M., Jayaram, J., 2005. Internal and external integration for product development: the contingency effects of uncertainty, equivocality, and platform strategy. Decision Sciences 36 (1), 97-133.

Kulp, S., Lee, H., Ofek, E., 2004. Manufacturer benefits from information integration with retail customers. Management Science 50 (4), 431-444.

Kwon, D., Watts, S., 2006. IT valuation in turbulent times. Journal of Strategic Information Systems 15 (4), 327-354.

Lee, H., So, K., Tang, C., 2000. The value of information sharing in a two-level supply chain. Management Science 46 (5), 626-643.

Lee, H., Padmanabhan, V., Whang, S., 2004. Information Distortion in a Supply Chain: The Bullwhip Effect. Management Science 50 (12), 1875-1886

Lee, H., Whang, S., 2000. Information sharing in a supply chain. International Journal of Manufacturing Technology and Management 1 (1), 1-93.

Levy, D., 1997. Lean production in an international supply chain. Sloan Management Review 38 (2), 94-102.

Li, G., Yan, H., Wang, S., Xia, Y., 2005. Comparative analysis on value of information sharing in supply chains. Supply Chain Management: An International Journal $10(1), 34-46$.

Li, J., Sikora, R., Shaw, M., Tan, G., 2006. A strategic analysis of inter organizational information sharing. Decision Support Systems 42 (1), 251-266.

Li, M., Ye, L., 1999. Information technology and firm performance: linking with environmental, strategic and managerial contexts. Information \& Management 35 (1), 43-51.

Lieberman, M., Helper, S., Demeester, L., 1999. The empirical determinants of inventory levels in high-volume manufacturing. Production and Operations Management 8 (1), 44-55.

Lu, Y., Ramamurthy, K., 2004. Does information technology always lead to better firm performance? The role of environmental dynamism. Proceedings of International Conference on Information Systems. pp. 249-262.

MacDuffie, J., Sethuraman, K., Fisher, M., 1996. Product variety and manufacturing performance: evidence from the international automotive assembly plant study. Management Science 42 (3), 350-369.

Malhotra, A., Gosain, S., El Sawy, O., 2007. Leveraging standard electronic business interfaces to enable adaptive supply chain partnerships. Information Systems Research 18 (3), 260-279.

McGuckin, R., Nguyen, S., 1995. On productivity and plant ownership change: new evidence from the longitudinal research database. The Rand Journal of Economics 26 (2), 257-276.

Melville, N., Gurbaxani, V., Kraemer, K., 2007. The productivity impact of information technology across competitive regimes: the role of industry concentration and dynamism. Decision Support Systems 43 (1), 229-242.

Melville, N., Kraemer, K., Gurbaxani, V., 2004. Review: information technology and organizational performance: an integrative model of IT business value. MIS Quarterly 28 (2), 283-322.

Mithas, S., Tafti, A., Mitchell, W., 2013. How a firm's competitive environment and digital strategic posture influence digital business strategy. MIS Quarterly 37 (2), 511-536.

Mukhopadhyay, T., Kekre, S., Kalathur, S., 1995. Business value of information technology: a study of electronic data interchange. MIS Quarterly 19 (2), $137-156$.

Nijman, T., Verbeek, M., 1992. Nonresponse in panel data: the impact on estimates of a life cycle consumption function. Journal of Applied Econometrics 7 (3), 243-257.

Nunnally, J., 1967. Psychometric Theory. McGraw-Hill, New York.

O'Leary-Kelly, S., Flores, B., 2002. The integration of manufacturing and marketing/sales decisions: impact on organizational performance. Journal of Operations Management 20 (3), 221-240.

Overby, E., Bharadwaj, A., Sambamurthy, V., 2006. Enterprise agility and the enabling role of information technology. European Journal of Information Systems 15 (2), $120-131$.

Pavlou, P., El Sawy, O., 2006. From IT leveraging competence to competitive advantage in turbulent environments: the case of new product development. Information Systems Research 17 (3), 198-227.
Pfaffermayr, M., 1999. Ownership advantages, foreign production and productivity: evidence from Austrian manufacturing firms. Review of Industrial Organization 15 (4), 379-396.

Podsakoff, P., MacKenzie, S., Lee, J., Podsakoff, N., 2003. Common method biases in behavioral research: a critical review of the literature and recommended remedies. Journal of Applied Psychology 88 (5), 879-903.

Raghunathan, S., 2003. Impact of demand correlation on the value of and incentives for information sharing in a supply chain. European Journal of Operational Research 146 (3), 634-649.

Raghunathan, S., 2001. Information sharing in a supply chain: a note on its value when demand is nonstationary. Management Science 47 (4), 605-610.

Rai, A., Patnayakuni, R., Seth, N., 2006. Firm performance impacts of digitally enabled supply chain integration capabilities. MIS Quarterly 30 (2), 225-246.

Rajagopalan, S., Malhotra, A., 2001. Have U. S. manufacturing inventories really decreased? Manufacturing \& Service Operations Management 3 (1), 14-24

Ramirez, R., Melville, N., Lawler, E., 2010. Information technology infrastructure, organizational process redesign, and business value: an empirical analysis. Decision Support Systems 49 (4), 417-429.

Rosenzweig, E., 2009. A contingent view of e-collaboration and performance in manufacturing. Journal of Operations Management 27 (6), 462-478.

Rumyantsev, S., Netessine, S., 2007. What can be learned from classical inventory models? A cross-industry exploratory investigation. Manufacturing \& Service Operations Management 9 (4), 409-429.

Sabath, R., Fontanella, J., 2002. The unfulfilled promise of supply chain collaboration. Supply Chain Management Review 6 (4), 24-29.

Sargan, J., 1958. The estimation of economic relationships using instrumental variables. Econometrica 26 (3), 393-415.

Sawhney, R., 2013. Implementing labor flexibility: a missing link between acquired labor flexibility and plant performance. Journal of Operations Management 31 $98-108$.

Schouten, F., Eijs, M., Heuts, R., 1994. The value of supplier information to improve management of a retailer's inventory. Decision Sciences 25 (1), 1-14

Setia, P., Venkatesh, V., Joglekar, S., 2013. Leveraging digital technologies: how information quality leads to localized capabilities and customer service performance 37 (2), 565-590.

Shah, R., Ward, P., 2003. Lean manufacturing: context, practice bundles, and performance. Journal of Operations Management 21 (2), 129-149.

Sila, I., 2010. Do organisational and environmental factors moderate the effects of internet-based interorganisational systems on firm performance. European Journal of Information Systems 19 (5), 581-600.

Spekman, R., Kamauff, J., Myhr, N., 1998. An empirical investigation into supply chain management a perspective on partnerships. International Journal of Physica Distribution Logistics Management 28 (8), 630-650.

Srinivasan, K., Kekre, S., Mukhopadhyay, T., 1994. Impact of electronic data interchange technology on JIT shipments. Management Science 40 (10), 1291-1304.

Steckel, J., Gupta, S., Banerji, A., 2004. Supply chain decision making: will shorter cycle times and shared point-of-sale information necessarily help? Management Science 50 (4), 458-464.

Strader, T., Lin, F., Shaw, M., 1999. The impact of information sharing on order fulfillment in divergent differentiation supply chains. Journal of Global Information Management 7 (1), 16-25.

Suarez, F., Cusumano, M., Fine, C., 1996. An empirical study of manufacturing flexibility in printed circuit board assembly. Operations Research 44 (1), 223-240.

Tallon, P., Pinsonneault, A., 2011. Competing perspectives on the link between strategic information technology alignment and organizational agility: insights from a mediation model. MIS Quarterly 35 (2), 463-486

Tallon, P., 2007. Does IT pay to focus? An analysis of IT business value under single and multi-focused business strategies. Journal of Strategic Information Systems 16 (3), 278-300.

Tallon, P., Kraemer, K., Gurbaxani, V., 2000. Executives' perceptions of the business value of information technology: a process-oriented approach. Journal of Management Information Systems 16 (4), 145-173.

Teece, D., Pisano, G., Shuen, A., 1997. Dynamic capabilities and strategic management. Strategic Management Journal 18 (7), 509-533.

Treville, S., Shapiro, R., Hameri, A., 2004. From supply chain to demand chain: the role of lead time reduction in improving demand chain performance. Journal of Operations Management 21 (6), 613-627.

U.S. Census Bureau, 2010. 〈http://www.census.gov/econ/overview/ma0300.html〉.

U.S. Census Bureau, 2010. 〈http://www.census.gov/econ/overview/ma0500.html).

U.S. Census Bureau, 2001. Geographic Area Statistics: 2001.

Venkatesh, V., 2010. Call for papers-special issue: IT, supply chain, and services. Journal of Operations Management.

Wade, M., Hulland, J., 2004. Review: the resource-based view and information systems research: review, extension, and suggestions for future research. MIS Quarterly 28 (1), 107-142.

Wagner, J., 2002. The causal effects of exports on firm size and labor productivity: first evidence from a matching approach. Economics Letters 77 (2), 287-292.

Wailgum, T., 2010. Supply Chain Management Definition and Solutions. (http://www.cio.com/article/40940/Supply_Chain_Management_Definition_and Solutions? page $=3 \#$ scm_collaboration $\rangle$.

Weill, P., 1992. The relationship between investment in information technology and firm performance: a study of the valve manufacturing sector. Information Systems Research 3 (4), 307-333.

White, H., 1980. A heteroskedasticity-consistent covariance matrix estimator and a direct test for heteroskedasticity. Econometrica 48 (4), 817-838. 
Wong, C., Boon-itt, S., Wong, C., 2011. The contingency effects of environmental uncertainty on the relationship between supply chain integration and operational performance. Journal of Operations Management 29 (6), 604-615.

Wooldridge, J., 2002. Econometric Analysis of Cross Section and Panel Data. MIT, Press, Cambridge.

Yao, Y., Zhu, K., 2012. Do electronic linkages reduce the bullwhip effect? An empirical analysis of the U.S. manufacturing supply chains. Information Systems Research 23 (3), 1042-1055.
Zhu, K., Kraemer, K., 2005. Post-adoption variations in usage and value of e-business by organizations: cross-country evidence from the retail industry. Information Systems Research 16 (1), 61-84.

Zhu, K., Kraemer, K., 2002. E-commerce metrics for net-enhanced organizations: assessing the value of e-commerce to firm performance in the manufacturing sector. Information Systems Research 13 (3), 275-295.

Zuboff, S., 1985. Automate informate-the 2 faces of intelligent technology. Organizational Dynamics 14 (2), 4-18. 